\title{
MULTI-OBJECTIVE PERMUTATION AND NON-PERMUTATION FLOW SHOP SCHEDULING PROBLEMS WITH NO-WAIT: A SYSTEMATIC LITERATURE REVIEW
}

\author{
Harpreet Singh ${ }^{1, *}$, Jaspreet Singh Oberoi ${ }^{2}$ And Doordarshi Singh ${ }^{2}$
}

\begin{abstract}
Flow shop scheduling is a type of scheduling where sequence follows for each job on a set of machines for processing. In practice, jobs in flow shops can arrive at irregular times, and the no-wait constraint allows the changes in the job order to flexibly manage such irregularity. The flexible flow shop scheduling problems with no-wait have mainly addressed for flow optimization on the shop floor in manufacturing, processing, and allied industries. The scope of this paper is to identify the literature available on permutation and non-permutation flow shop scheduling with no-wait constraint. This paper organizes scheduling problems based on performance measures of variability and shop environments. The extended summary of two/three-machine and $m$-machine problems has been compiled, including their objectives, algorithms, parametric considerations, and their findings. A systematic appearance of both conceptual and analytical results summarizes various advances of the no-wait constraint. The paper includes independently investigated problems and suggestions for future research directions.
\end{abstract}

Mathematics Subject Classification. 97M40.

Received August 17, 2019. Accepted May 19, 2020.

\section{INTRODUCTION}

The multi-objective flow shop scheduling problem is the type of production scheduling problems. The production schedule is an arrangement of controlling, optimizing, and work loading in the manufacturing process. In some, the jobs processed in a series of operations in the same sequence, i.e., following the same route in some manufacturing and assembly facilities. This environment is referred to as a flow shop and is a critical element of scheduling problems. Its significance and practical implementation to the industry sector have attracted researchers to study it from distinct angles. The methodological restraints qualify the raw processing order for every job in a flow shop. It is essential to develop robust and dynamic algorithms to improve production efficiency and enhance the optimization of manufacturing resources to enhance the competitive strength.

The decision support system (DSS) for multi-objective project management and scheduling has presented under the selection of advanced manufacturing technologies [3]. An approach is proposed to solve multi-criteria decision problems with mathematical programming models [34]. Gunasekaran et al. [47] realized the importance

Keywords. Flexible scheduling, flow shop, non-permutation, no-wait and permutation.

1 Mechanical Engineering Department, Faculty of Engineering \& Technology, I.K. Gujral Punjab Technical University, Jalandhar (Kapurthala), Punjab 144603, India.

2 Mechanical Engineering Department, Baba Banda Singh Bahadur Engineering College, Fatehgarh Sahib, Punjab 140407, India.

*Corresponding author: harpreet.mech9@gmail.com 


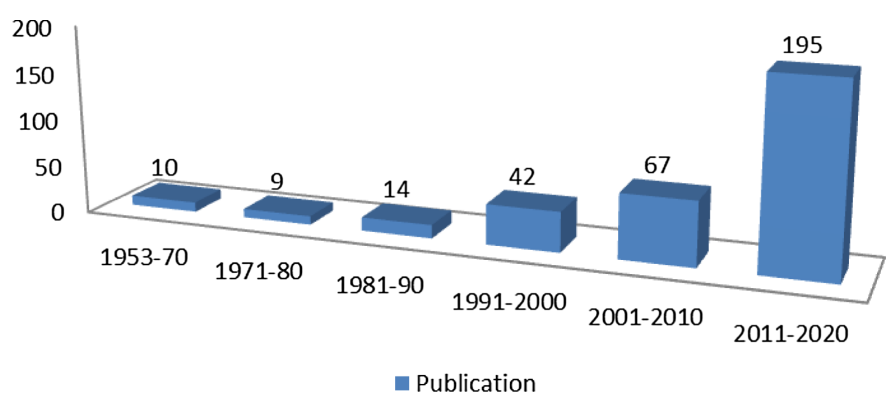

FIGURE 1. Number of papers published in ten-year periods (Source: Sec. quantitative analysis of literature).

of flexible manufacturing systems in increasing productivity and quality. Strategic management of sustainable manufacturing operations has featured a comprehensive survey of sustainability efforts [33]. It has highlighted the successful techniques used by different companies for flexible practices. A mixed-integer linear programming model is framed to show alternative critical activities and relationships [37].

The no-wait constraint processing of two successive operations of a job without any interruptions is the origin of occurring in scheduling. The research concern in scheduling with the no-wait constraint has begun in the 1970s. Several research papers have appeared since the mid-1990. Therefore, the current review paper provides a review of the scheduling research with the no-wait constraint from the mid-1950s to the present. Most of the literature on dealing FSP has focused on single-criteria scheduling. However, many objectives are taken in several real-life dynamic situations. The traditional approaches to solve single-criteria FSP and to challenge small-sized scheduling problems are widely available. However, despite the relative success of exact and approximation algorithm models, they are still incompetent in concentrating medium-and-large scale problems and are too complicated for real-world problems. In past decades, the architecture of multi-objective problems and programming skills to tackle FSP with multiple objectives has increased (Fig. 1). The current work aims to provide researchers with an updated analysis of the theoretical and practical topics of MFSP and future study trends.

This paper reviews over 300 articles with the no-wait constraint on scheduling permutation and nonpermutation issues. It also addresses issues based on available shop environments, associated performance measures and other variables. Some prospective study issues suggested that separately addressed problems studied and less addressed problems identified.

\section{The PERMUTATION AND NON-PERMUTATION FLEXIBLE FLOW SHOP SCHEDULING PROBLEMS}

The permutation flow shop (PFS) is one where each job processes in the same order. Therefore, once the job sequence on the first machine is fixed in a permutation flow shop, it will be the same in the rest of the stages. This problem is expressed as $F m \mid$ prmu $\mid C_{\max }$ [150]. The flow shop scheduling problem with makespan can be denoted as $F 3 \mid C_{\max }, F$ as introduced by [78], and $F m \| C_{\max }, F$, as suggested by [27,145]. There are some requirements of PFS: preemption is not allowed; all jobs are independent and are available for processing at time zero; the machines are available continuously; the setup times of jobs on machines are sequence-independent and included in the processing times [86,113]. The no-wait performance measures of PFS and NPFS problems are categorized into three groups: completion time measures $\left(C_{\max }, F\right)$; due date measures $(L, T)$; measures based on inventory and utilization costs $[35,38,89]$.

The non-permutation flow shop scheduling problem (NPFS) is a simplification of the conventional permutation flow shop scheduling problem that permits job order changes on different machines. NPFS offers in industrial 
TABLE 1. Permutation and non-permutation with no-wait objective function(s).

\begin{tabular}{lll}
\hline \hline Problem & Problem type & Status \\
\hline$F$ & Single-objective function & \\
$F$ & Performance measure & \\
$F 2 / F 3 / f 1, f 2$ & Two/three machine problem with bi-objective & \\
$F 2 / F 3 / f 1, f 2, \ldots, f k$ & Two/three machine problem with multi-objective & Permutation/ \\
$F m / f 1, f 2$ & $m$-machine problem with bi-objective & non- \\
$F m / f 1, f 2, \ldots, f k$ & $m$-machine problem with multi-objective & permutation/ \\
$F 2 / F 3 / w 1, w 2$ & Two/three machine problem with weighted-objective & both \\
$F m / w 1, w 2$ & $m$-machine problem with weighted-objective & \\
$F p / p 1, p 2$ & $m$-machine problem with pareto-optimal objective & \\
$F m / Z$ cost & $m$-machine problem with cost-objective function & \\
$F m / \varepsilon, ¥, \theta, \Phi$ & $m$-machine problem with constraint-bound approach & \\
\hline
\end{tabular}

model applications even though its complexity. The flow shop arrangements are usual in production configurations where machine stages $m=(1,2, \ldots, m)$ process job sets $n=(1,2, \ldots, n)$. Each job follows a machine sequence in the specific order, i.e., $\left(m_{1}, m_{2}, \ldots, m_{n}\right)$ [143]. If the job order is uniform for $m$-machines, then the schedule is known as a permutation. The problem is expressed as $F 2 \| C_{\max }, F[109]$ and $F m\|p r m u\| C_{\max }$ [144]. Otherwise, if the processing order can vary in $m$-machine stages, and the permutation criterion is flexible, then the problem is called a non-permutation flow shop scheduling problem. The problem is represented as $F 2 \mid$ block $\mid C_{\max }$ [148]. There are some requirements of NPFS besides specifications: all the jobs and machines should be available at the start; a job can be processed by one machine at one time; the experimental data should be deterministic and known in prior [112].

The configuration of PFS and NPFS approaches are similar; the third item is the most significant potential difference between them, i.e., no-wait constraint. In some instances, PFS and NPFS problems also consider the intermediate buffers with infinite capacity and being so smoothly compatible in the flow shop. On the other hand, both approaches cannot find an optimal solution in the absence of intermediate buffers [121]. Besides the three key specifications and requirements described above in the standard form of PFS and NPFS, this explanation does not cover the whole spectrum of PFS and NPFS problems but helps as a framework for them. All the various PFS and NPFS measures can be validated by adding no-wait constraints.

The permutation and non-permutation techniques developed recently are used to handle MFSP. Their comprehensive surveys with the no-wait constraint, future developments, and challenges are relatively very limited. Johnson [53] studied two and three-stage industrial systems, which included setup times with the no-wait constraint. There have been a few case studies about multi-criterion scheduling available in the technical literature by [46,98,99,112,113,156]. Ahmadizar and Farahani [2], Han et al. [51], Minella et al. [86], Rabadi [118], Pessoa and Andrade [111], Shahvari and Logendran [132], and Tadayon and Salmasi [152] reviews do not discuss future directions and challenges thoroughly. Several other approaches emerged after these papers were published. Most of the flow shop scheduling literature is restricted to a specific case, the permutation and non-permutation with no-wait. The literature on this issue is emerged in the last decade, suggesting that the subject is an active research field. In this paper, we will focus on permutation and non-permutation no-wait flow shop groups with makespan objective minimization. Different methods have used to solve permutation, and non-permutation no-wait scheduling problems are abbreviated (attached in supplementary file). The summary of problems and approaches for permutation and non-permutation with the no-wait constraint are representing the two/three-machine, m-machine objective functions (Tab. 1), HF scheduling problem, permutation problem, $S D S T$ problem, the results on $C_{\max }$ for F2/F3, block problem and no-idle problem (Tab. 2). 
TABLE 2. Summary of problems and approaches for permutation and non-permutation with no-wait.

\begin{tabular}{|c|c|c|c|c|}
\hline Problem type & $\begin{array}{l}\text { Status } \\
\text { (permutation) }\end{array}$ & Problem & Algorithm & Reference \\
\hline \multirow{7}{*}{ Bi-objective $n / 2 / 3 / P / f$} & $\checkmark$ & $F 3 \| C_{\max }, F$ & $\mathrm{~B} \& \mathrm{~B}$ & {$[78]$} \\
\hline & $\checkmark$ & $F 2 \| C_{\max }, F$ & Heuristics, JA & {$[109]$} \\
\hline & $\checkmark$ & $F 2(P M)|n w t| C_{\max }$ & GA & {$[160]$} \\
\hline & $x$ & $F 2 \| C_{\text {max }}, Z_{\text {cost }}$ & MILP & {$[175]$} \\
\hline & $x$ & $F 2 \| C_{\max }, T$ & $\begin{array}{l}\text { Priority scheduling } \\
\text { approach }\end{array}$ & {$[58]$} \\
\hline & $\checkmark$ & $F 3\left|w_{i 1}, w_{i 2}\right| C_{\max }$ & $\mathrm{B} \& \mathrm{~B}$ & {$[57]$} \\
\hline & $x$ & $F 3\left|h e_{i j n}, j, \varepsilon\right| C_{\max }$ & $\begin{array}{l}\text { NSGA-II, MOPSO, GA, and } \\
\text { SPEA-II }\end{array}$ & {$[141]$} \\
\hline \multirow{14}{*}{ Bi-objective $n / m / P / f$} & $x$ & $F m \| L_{\max }, F$ & MCDP & {$[71]$} \\
\hline & $\checkmark$ & $F m|p r m u| C_{\max }$ & Various conditions & {$[150]$} \\
\hline & $\checkmark$ & $F m \| C_{\max }, F$ & TSH & {$[27]$} \\
\hline & $\checkmark$ & $F m \| C_{\max }, F$ & $\mathrm{~N} \& \mathrm{M}$ heuristics & {$[95]$} \\
\hline & $\checkmark$ & $F m \mid C_{\max }, F$ & MNEH, MSA & {$[79]$} \\
\hline & $x$ & $F m \| C_{\max }, F$ & ACS & {$[170]$} \\
\hline & $\checkmark$ & $F m \| C_{\max }, F$ & JA based heuristics & {$[38]$} \\
\hline & $\checkmark$ & $H F 2 \| C_{\max }, T$ & BOLS & {$[94]$} \\
\hline & $\checkmark$ & $F m \mid$ prmu $\mid C_{\max }$ & EDA & {$[161]$} \\
\hline & $\checkmark$ & $F m \| C_{\max }, F$ & TS, SA & {$[18]$} \\
\hline & $x$ & $J \| C_{\max }, F$ & GA & {$[127]$} \\
\hline & $\checkmark$ & $F m \mid$ prum $\mid C_{\max }$ & BS-HH & {$[73]$} \\
\hline & $\checkmark$ & $F m \| C_{\max }, F$ & Polynomial algorithm & {$[24]$} \\
\hline & $\checkmark$ & $F 2 \|\left(A G_{1,2}\right) \mid C_{\max }, T_{\max }$ & h-MOEA & {$[41]$} \\
\hline \multirow{18}{*}{ Multi-objective $n / m / P / f$} & $\checkmark$ & $F m \| C_{\max }, F$ & DTA & {$[145]$} \\
\hline & $\checkmark$ & $F m \| C_{\max }, F$ & $\mathrm{CDA}$ & {$[22]$} \\
\hline & $\checkmark$ & $F m|p r m u| C_{\max }$ & $\mathrm{B} \& \mathrm{~B}$ & {$[114]$} \\
\hline & Both & $F m \mid S D S T$, block $\mid C_{\max }, T$ & TSP-heuristics & {$[48]$} \\
\hline & $\checkmark$ & $F m|S D S T| C_{\max }, F$ & Heuristics & {$[50]$} \\
\hline & $x$ & $F m \| C_{\max }, L_{\max }$ & Heuristics, LB & {$[125]$} \\
\hline & $\checkmark$ & $F m \mid$ prmu $\mid C_{\max }, F$ & SA, TS, heuristics & {$[147]$} \\
\hline & $\checkmark$ & $F m|p r m u| T_{\max }, F$ & LRT & {$[75]$} \\
\hline & $\checkmark$ & $F m\left|s_{i j k}, p r m u\right| C_{\max }$ & $\mathrm{B} \& \mathrm{~B}$ & {$[84]$} \\
\hline & Both & Fm|prmu,block $\mid C_{\max }$ & TS, heuristics & {$[44]$} \\
\hline & $\checkmark$ & $F m \| T_{\max }, C_{\max }$ & IA & {$[4]$} \\
\hline & Both & $F m|S D S T| C_{\max }$ & TS-heuristics & {$[172]$} \\
\hline & $\checkmark$ & $F m|n w t, p r m u| C_{\max }$ & HDPSO & {$[105]$} \\
\hline & $\checkmark$ & $F m \mid$ prmu $\mid C_{\max }$ & NEGA-VNS & {$[183]$} \\
\hline & $\checkmark$ & $F m \| C_{\max }, F, C_{w}$ & MOACSA & {$[165]$} \\
\hline & Both & $F m \mid$ prmu, block $\mid C_{\max }$ & DLHS & {$[106]$} \\
\hline & $x$ & $H F m(P M) \| C_{\max }, Z_{\text {cost }}$ & GA, heuristics & {$[182]$} \\
\hline & $\checkmark$ & $F m|n w t, p r m u| C_{\max }$ & HDDE & {$[28]$} \\
\hline
\end{tabular}


TABLE 2. (Continued.)

\begin{tabular}{|c|c|c|c|c|}
\hline Problem type & $\begin{array}{l}\text { Status } \\
\text { (permutation) }\end{array}$ & Problem & Algorithm & Reference \\
\hline & $\checkmark$ & $H F m(P M) \| C_{\max }, F$ & $\mathrm{PSO}$ & {$[69]$} \\
\hline & $x$ & $F m|S D S T| Z_{\text {pih_cost }}, I_{\text {sum }}$ & GA & {$[10]$} \\
\hline & $\checkmark$ & $F m \mid S D S T$, prmu $\mid C_{\max }$ & HGA & {$[88]$} \\
\hline & $\checkmark$ & $F m \mid S T_{s d}$, no-wait,$r_{j} \mid C_{\max }$ & ECS & {$[96]$} \\
\hline & $\checkmark$ & Fm|prum, $S D S T \mid C_{\max }$ & $\mathrm{MBO}$ & {$[14]$} \\
\hline & $\checkmark$ & $F m \mid$ prmu $\mid C_{\max }, F$ & MONEH, MMOIG & {$[31]$} \\
\hline & $\checkmark$ & $F m|p r m u| C_{\max }, \Psi$ & BRILS & {$[39]$} \\
\hline & $\checkmark$ & $F m|p r m u| C_{\max }$ & GA, AIS & {$[15]$} \\
\hline & $\checkmark$ & $H F m\left|S D_{S T}, r_{j}, s k i p\right| C_{w}, T_{w}$ & TS, path-relinking & {$[131]$} \\
\hline & $\checkmark$ & $F m|n w t| C_{\max }, D$ & HDTPL & {$[133]$} \\
\hline & $\checkmark$ & $F m|p r m u| C_{\max }$ & NS-SGDE & {$[133]$} \\
\hline & $\checkmark$ & $F m|n w t| C_{\max }, F$ & ACO-SA & {$[122]$} \\
\hline & $\checkmark$ & $F\left|n w t, d_{j}\right| C_{\max }$ & Enumeration algorithm & {$[128]$} \\
\hline & $\checkmark$ & $F m|n w t| C_{\max }, I_{\text {sum }}$ & AIT heuristic, ISA & {$[168]$} \\
\hline & $x$ & $H F m|l s m| C_{\max }$ & Heuristics & {$[62]$} \\
\hline & $x$ & $F m \| Z_{\text {cost }}, W_{\text {ave }}$ & I-ICA & {$[120]$} \\
\hline & $\checkmark$ & $F m|p r m u| C_{\max }, T_{\max }, F$ & CMA & {$[29]$} \\
\hline & $\checkmark$ & $F m\left|n w t, d_{j}\right| C_{\max }$ & Enumeration algorithm & {$[129]$} \\
\hline & $\checkmark$ & $F F m|S D S T| C, T_{\max }, W_{w}$ & I-HGA & {$[76]$} \\
\hline & Both & $F m \mid$ prmu, block $\mid C_{\max }, F$ & MBGA, NSGA-II & {$[102]$} \\
\hline & $x$ & $F m|S D S T| F_{\text {ave }}, T$ & CDRs, GP & {$[56]$} \\
\hline & $\checkmark$ & $F m \mid$ prmu, no-idle $\mid C_{\max }$ & MANEH, GVNS-SA & {$[136]$} \\
\hline & $\checkmark$ & $F m|p r m u| C_{\max }$ & SS, DT & {$[43]$} \\
\hline & $\checkmark$ & Fm $\mid$ prum, no-idle $\mid \sum T$ & $\mathrm{I}(\mathrm{fj}, \mathrm{d})-\mathrm{ICH}$ & {$[97]$} \\
\hline & $\checkmark$ & $F m|p r m u| C_{\max }, \Theta$ & IGA & {$[101]$} \\
\hline & $\checkmark$ & $F \mid$ prmu $, S D S T \mid C_{\max }, F$ & EMBO, STH heuristic & {$[142]$} \\
\hline & $x$ & $F H m(P M) \mid$ skip $\mid C_{\max }$ & Heuristics, dispatching rules & {$[32]$} \\
\hline & $\checkmark$ & $F m \mid$ prmu $, d_{O}, a k\left|C_{\max }\right| T_{\max }$ & IGA & {$[77]$} \\
\hline & $\checkmark$ & $H F m\left|S T_{s d}, r_{j}, M_{j}, s k i p\right| \sum w_{j}, T_{j}$ & TS/PR, PSO/LSA & {$[132]$} \\
\hline & $\checkmark$ & $F m \mid$ no-wait $\mid C_{\max }$ & DWWO & {$[177]$} \\
\hline & $\checkmark$ & $F m \mid r_{j}$, perm $\mid \sum F\left(C_{j}\right)$ & ILS, IGS, BRKGA, VND & {$[111]$} \\
\hline & $x$ & $F m|P I C, J T T| C_{\max }, Z_{\text {cost }}$ & HDMGWO & {$[117]$} \\
\hline & $\checkmark$ & $F m \mid$ block $\mid C_{\max }, \sum T_{j}$ & MODWWO & {$[139]$} \\
\hline & $\checkmark$ & $F m \mid \gamma, \rho$, perm $\mid C_{\max }$ & Greedy heuristic & {$[64]$} \\
\hline & $\checkmark$ & Fm $\mid$ blocking $\mid C_{\max }$ & DIWO & {$[138]$} \\
\hline & $\checkmark$ & $F m \mid S T_{S I}$, no-wait $\mid \varepsilon\left(\sum T_{j} \mid C_{\max }\right)$ & $\mathrm{PA}$ & {$[7]$} \\
\hline \multirow{2}{*}{ Multi-objective $n / 2 / 3 / P / f$} & $\sqrt{ }$ & $F 2 \|$ prmu, block $\mid C_{\max }$ & TS & {$[146]$} \\
\hline & $\checkmark$ & $F 2|p r m u, n w t| C_{\max }$ & BAT, GA & {$[115]$} \\
\hline
\end{tabular}


TABLE 3. Special permutation results with no-wait, considering makespan as objective.

\begin{tabular}{lll}
\hline \hline Problem & Comments & Reference \\
\hline$F m\left|S_{n s d}, R_{k m}\right| C_{\max }$ & NPFS approach does not ensure optimality. & {$[50]$} \\
& NPFS makespan worst case: & \\
$F m \mid$ removal times $\left(R_{i k}\right) \mid C_{\max }$ & single time $(m-1)$ and $(k-1) /(m-k)$ PFS makespan. & {$[172]$} \\
& NPFS approach does not ensure optimality. & NPFS makespan worst case: \\
$F m \mid$ time delays $\left(T_{i, n, m}\right) \mid C_{\max }$ & $1 / 2$ times PFS makespan. \\
& NPFS approach does not ensure optimality. \\
$F m \mid$ time delays $\left(C_{i, j}\right) \mid C_{\max }$ & NPFS makespan worst case: \\
& $1 / 2$ times $\sum\left(I_{c}+P_{c}\right) /\left(C T_{i, n, m}\right)$ PFS makespan. \\
& NPFS approach does not ensure optimality. \\
$F m \mid$ learning effect $\left(\sum_{j}, \mu_{j}, P_{j, i}\right) \mid C_{\max }$ & NPFS makespan worst case: \\
$F m \mid$ block $\left(m_{\pi}, m *\right) \mid C_{\max }$ & $\left(S T_{i, q}=0\right)$ PFS makespan. \\
& NPFS approach does not ensure optimality. \\
& NPFS approach does not ensure optimality. \\
& NPFS makespan worst case: \\
& $3 / 4$ times PFS makespan. \\
\hline
\end{tabular}

\subsection{Permutation and non-permutation complexity: special cases}

Since permutation and non-permutation with no-wait are far from being a subject of extensive research, we compile some significant outcomes that can serve as guidance for beginners or as a state-of-the-art resource for professional researchers or field practitioners. Firstly, PFS groups must achieve the same or better results as NPFS groups for similar problem-case since the former and latter comprise all the solutions of each other cases and more. The additional computational effort required to solve complex NPFS problems compared to PFS problems with no-wait is a highly relevant topic (Tabs. 3 and 4).

Johnson [53] presented the oldest result of PFS scheme for the general two-and-three stage production schedules (permutation) where each job can pass through stage one, and then stage two. Each machine can handle only one item at a time, without blocking the optimal solution. There are two arbitrary (positive) numbers given for each item representing the setup plus work time for that item to pass through each stage. Thus, for the case of $F 2 \mid C_{\max }, F$ is optimal. This result is clearly validated in [59].

In consequence, the PFS approach becomes constructive for systems with more than three machines [24]. This analysis is being refined by newer results (Tab. 3). These rows address some special cases such as bound on the worst-case and where NPFS does not validate optimality even in $m$-machine cases due to some of the conditions of [25] which do not apply.

Other relevant research outcomes (permutation) describing complexities are:

- For a broader range of no-idle and no-wait constraints, it is more likely that the PFS schemes outperform NPFS schemes increase [26].

- The scheduling environment based on objective functions tardiness and the makespan would benefit more from the PFS scheme than NPFS scheme as the cumulative error is reduced to $60 \%$ [6]; and with setup times to tardiness and makespan, the cumulative error is reduced to $50 \%$ [7].

- The chances that the PFS scheme outperforms the NPFS approach for a range of sequence-dependent setup times $[23,67,90]$.

- The possibilities of PFS schemes outperforming NPFS schedules increase for a range of processing times $[36,74]$.

- For a broader range of release-date constraints, the PFS scheme outperforms the NPFS scheme $[128,129]$. 
TABLE 4. Special non-permutation results with no-wait, considering makespan as objective.

\begin{tabular}{lll}
\hline \hline Problem & Comments & Reference \\
\hline$F 2 \mid$ learning effect $\left(\pi, P_{j, i}\right) \mid C_{\max }$ & PFS approach does not ensure optimality. & {$[74]$} \\
& PFS makespan worst case: & \\
& 2 times NPFS makespan. & {$[164]$} \\
$F 2 \mid$ time delays $\left(d_{j}\right) \mid C_{\max }$ & PFS approach does not ensure optimality. & \\
& PFS makespan worst case: & {$[148]$} \\
$F 2 \mid$ removal times $\left(r_{i k}\right) \mid C_{\max }$ & $3 / 2$ times NPFS makespan. & PFS makespan worst case: \\
$F 2 \mid$ block $\mid C_{\max }$ & $3 / 2$ times NPFS makespan, and does not ensure optimality. & {$[148]$} \\
$F m \mid C_{\max }, F$ vs. $F m|p r m u| C_{\max }$ & PFS approach does not ensure optimality. & {$[170]$} \\
& PFS makespan worst case: & 2 min $(m, n)$ times NPFS makespan. \\
\hline
\end{tabular}

Conway et al. [25] presented the oldest result of the NPFS scheme for the flow shop group. The sequence (non-permutation) can be the same for the first and second machines without hindering the optimal solution. The optimum sequence of $n$-jobs is processing through $m$-machines to minimize flow time. The smaller the completion time, the less the overall flow time increases. Thus, for the case $F m \mid C_{\max }, F$ is optimal. This result is clearly validated in [108].

In consequence, the NPFS approach becomes constructive for two/three machines [58]. This analysis is being refined by newer results (Tab. 4). These rows address some special cases such as bound on the worst case, and where NPFS does not validate optimality in two/three and $m$-machine cases, due to some of the conditions of [25] which do not apply. The first four rows address special cases of bound on the worst case, and the last row indicates a particular case where PFS does not validate optimality in $m$-machine cases, because of certain conditions suggested by [25].

Other research investigational outcomes (non-permutation) describing complexities are:

- The possibilities of NPFS schemes outperforming PFS schedules increase for a range of setup and processing times $[116,148]$.

- The makespan is $4 \%$ better in the NPFS scheme for a simple flow shop [153].

- The scheduling environments in which the objective functions are based on release-date and weighted tardiness would benefit more from the NPFS scheme than those in which they are grounded on completion time [164].

- It is more likely that the NPFS scheme outperforms the PFS scheme for a range of processing times $[169,170]$.

- For a broader range of minimal and maximal time lags, the chances that NPFS schemes outperform the PFS schemes in the number of tardy jobs and the makespan as the primary and secondary criterion [30].

\section{TWO OR THREE-MACHINE NWFS PROBLEMS}

The two or three-machine minimum makespan flow shop with the no-wait in the process is NP-hard. This flow shop problem contains " $n$ " jobs simultaneously at time zero and to be processed by more than one machine(s) arranged in series with unlimited buffer in-process. It is required to plan " $n$ " jobs on machines; therefore, to reduce the makespan, e.g., the makespan can be minimized by finding non-permutation level $L: L(1), \ldots, L(n)$ of all jobs. These are based upon the criterion of approach(s), machine input(s), job, and time estimates such as SDST, permutation, non-permutation, tardiness, no-wait, completion time (Tab. 5). The sequence-independent setup time is followed by the sequence-dependent setup time (SDST). 


\subsection{Research results and recommendations on $C_{\max }$ for $F 2 / F 3$}

Ying and Lin [170] established an effective algorithm for the $F|k| C_{\max }$ problem. It has recommended the future research first as ACS offers many selections. The parameter sets should be thoroughly examined. Second, the advanced heuristic can be expended with distinct performance criteria to other production environments and the FSP. Ahmadizar and Farahani [2] created an open shop scheduling hybrid GA with specific operators. The algorithm suggested a crossover operator preserves the relative order of machine employment. Samarghandi and Behroozi [128] regarded the no-wait flow shop issue with release/due date restraints and makespan criteria with no-wait constraint and are NP-hard. The graph simulation of the problem with the exact enumeration algorithm has presented.

Salido et al. [127] represented an expansion of the conventional job-shop scheduling problem. Each job must be performed at distinct rates by one machine. Khorasanian and Moslehi [55] investigated the two-machine flow shop scheduling problem with blocking. Another factor was the first machine's preemption, multi-task flexibility, and makespan minimization as a criterion.

$\mathrm{Fu}$ et al. [41] suggested the future research work necessary for developing multi-agent scheduling models. Based on this scheduling issue, the machine breakdown to the deteriorated scheduling and finite buffers is suggested. Sioud and Gagne [142] implemented two high-performance algorithms to minimize the makespan to fix a permutation flow shop issue with SDSTs.

The second algorithm is an optimization of migrating birds, improved by a revised neighborhood search. The sources are a first leader selection process, a tabu list, swap and forward insertion moves, and a restart mechanism. Kim and Lee [57] recommended own research which can be drawn-out by considering multiple workstations. These are recommended in sequence-dependent setup times between the jobs on the machines.

Additional developments in the B\&B method will follow various branching patterns to substitute the rapid identification of ruling or governing scheduling decisions and decrease the result time [158]. Fonseca et al. [40] computed the heuristic h2, which contributes to the best average GAP. The loss grades charted by the heuristic h1 and the heuristics h2 shown to effort very fit with the Lagrangian method.

\section{4. m-MACHINE NWFS PROBLEMS}

The general $m$-machine flow shop problem is one where not all of the jobs follow the same sequence through " $m$ " machines, e.g., job 1 may go from machine 2 to $5,3,4$, and 1 , while job 2 may go from machine 3 to 1,2 , 4 , and 5 . The jobs are not preempted, and each job has " $m$ " tasks with processing time. A pairwise $J$-ordering, to be called the $J_{m}$-ordering, whose objective is the ordering of " $n$ " jobs in an $m$-machine flow shop. The sequence-dependent setup time (SDST) traces the sequence-independent setup time in the case of two/three machine problems.

\subsection{Research results and recommendations on $C_{\max }$ and $\sum C_{j}$ for $F m$}

Samarghandi and Behroozi [128] explained the computational results as the problem matures and ruling a possible result for $F m\left|n w t, d_{j}\right| C_{\max }$ is not an easy job. Analytical results discovered that the enumeration algorithm outperforms the supplementary models. A thorough computational study of the expansion enumeration algorithm is a feasible way forward for future studies. This research must include many large-scale test issues to demonstrate further the computational efficiency of the algorithm developed. Finally, the development of tight upper and lower bounds for $F m\left|n w t, d_{j}\right| C_{\max }$ is an exciting future direction of studies.

Deng and Wang [29] recommended the future work be focused on designing the CMA to solve the MODPFSP with other scheduling standards, such as cost minimization and carbon-efficiency. Nouri and Ladhari [102] performed a computational survey on different types of environments that demonstrate the effectiveness of the suggested NSGA-II algorithm. A comparative study between the algorithms such as ACO, Artificial Bee Colony, DE, MBGA, and PSO is an interesting prospect for future research. 
TABLE 5. Summary of research problems on $C_{\max }$ for $F 2 / F 3$.

\begin{tabular}{|c|c|c|c|}
\hline Algorithm & Problem & Findings & Reference \\
\hline $\mathrm{B} \& \mathrm{~B}$ & $F 3 \| C_{\max }, F$ & Lower bounds in each subgroup & {$[78]$} \\
\hline $\mathrm{B} \& \mathrm{~B}$ & $F 3 \| C_{\max }, F$ & $\begin{array}{l}\text { Rules for assigning the machines } \\
\text { and listing the jobs }\end{array}$ & {$[83]$} \\
\hline $\mathrm{B} \& \mathrm{~B}$ & $F 2 \| p r m u, r j \mid L_{\max }, F$ & $\begin{array}{l}\text { The flexibility of the capacity } \\
\text { constraints on the machines }\end{array}$ & {$[45]$} \\
\hline $\begin{array}{l}\text { Algorithms Gilmore-Gomory } \\
\text { algorithm }\end{array}$ & $F 2 \| n w t \mid C_{\max }, L_{\max }, F_{\text {ave }}$ & $\begin{array}{l}\text { Schedule with minimal maximum } \\
\text { lateness with minimal mean flow } \\
\text { times }\end{array}$ & {$[126]$} \\
\hline Johnson algorithm & $F 2 \| C_{\max }, F$ & $\begin{array}{l}\text { A single transporter and unlimited } \\
\text { buffer space between machines }\end{array}$ & {$[109]$} \\
\hline $\mathrm{B} \& \mathrm{~B}$ & $F 2 \| C_{\max }, F$ & $\begin{array}{l}\text { Effective solution approach to } \\
\text { complex FSP }\end{array}$ & {$[98]$} \\
\hline Hybrid GA and B\&B & $F 2 \| C_{\max }, F_{\text {ave }}$ & A GA based metaheuristic & [99] \\
\hline $\mathrm{B} \& \mathrm{~B}$ and constructive heuristic & $F 2 \| C_{\max }, T_{\max }$ & $\begin{array}{l}\text { Minimized the total number of } \\
\text { tardy jobs }\end{array}$ & {$[49]$} \\
\hline $\mathrm{TS}$ & $F 2 \|$ prmu, block $\mid C_{\max }$ & $\begin{array}{l}\text { Inter-machine buffer execution } \\
\text { with ready times, due dates and } \\
\text { rain-max cost criterion }\end{array}$ & {$[146]$} \\
\hline $\mathrm{B} \& \mathrm{~B}$ and heuristic & $F 2 \| C_{\max }, F$ & $\begin{array}{l}\text { The processing times of individual } \\
\text { jobs }\end{array}$ & {$[60]$} \\
\hline B\&B with effective branching rules & $F 3 \|$ prmu $\mid C_{\max }, \sum D$ & Hybrid permutation FSP & {$[167]$} \\
\hline GA & $F 2(P M)|n w t| C_{\max }$ & $\begin{array}{l}\text { Multiple parallel identical } \\
\text { machines schedule }\end{array}$ & {$[160]$} \\
\hline Kuhn-Munkres algorithm & $F 2|c o n, N W, L E| C_{\max }$ & $\begin{array}{l}\text { The convex resource-dependent } \\
\text { processing times }\end{array}$ & {$[74]$} \\
\hline BAT and GA & $F 2 \mid$ prmu, nwt $\mid C_{\max }$ & Neighborhoods in a sequence & {$[115]$} \\
\hline GA & $F 2 \| C_{\max }, F$ & $\begin{array}{l}\text { Reducing the total energy } \\
\text { consumption }\end{array}$ & {$[166]$} \\
\hline Mixed integer programming & $F 2 \| C_{\max }, T$ & $\begin{array}{l}\text { Parallel FSP reprocessing lines, } \\
\text { and parallel reassembly } \\
\text { workstations }\end{array}$ & {$[58]$} \\
\hline $\begin{array}{l}\text { The hybrid monkey search } \\
\text { algorithm }\end{array}$ & $F 2 \| C_{\max }, F$ & $\begin{array}{l}\text { A sub-population based NP-hard } \\
\text { type bi-objective function }\end{array}$ & {$[80]$} \\
\hline IDCOA & $F 2 \| C_{\max }, F$ & $\begin{array}{l}\text { Minimized the makespan of a } \\
\text { three-stage assembly FSP }\end{array}$ & {$[59]$} \\
\hline (BBO) & $F 2 \| C_{\max }, T$ & Finalized the interfering job sets & {$[157]$} \\
\hline Direct combinatorial algorithms & $F 2 \mid$ synmv, plbl $\mid C_{\max }$ & $\begin{array}{l}\text { Validated a mixed-integer program } \\
\text { and a two-stage approach }\end{array}$ & {$[21]$} \\
\hline $\begin{array}{l}\text { Hybrid multi-objective } \\
\text { evolutionary algorithm }\end{array}$ & $F 2 \|\left(A G_{1,2}\right) \mid C_{\max }, T_{\max }$ & $\begin{array}{l}\text { Minimized the makespan and the } \\
\text { total tardiness of the first agent } \\
\text { and the second agent respectively }\end{array}$ & {$[41]$} \\
\hline $\begin{array}{l}\text { A novel decoding method for job } \\
\text { permutation and GA }\end{array}$ & $\begin{array}{l}F H 3, F H m\left(\left(R M^{(k)}\right)_{M k=1}\right) \\
\left|M_{j}\right| \sum T_{j}\end{array}$ & $\begin{array}{l}\text { Dynamic scheduling to } \\
\text { avoid tightness problem and job } \\
\text { re-sequencing }\end{array}$ & {$[174]$} \\
\hline SWWO & $F 2|p r m u, n w t| C_{\max } \pi *$ & $\begin{array}{l}\text { A single-wave mechanism for the } \\
\text { NWFSP }\end{array}$ & {$[177]$} \\
\hline $\mathrm{B} \& \mathrm{~B}$ & $F 2 \mid C V a R$, no-wait $\mid C_{\max }$ & $\begin{array}{l}\text { Robust scheduling approach } \\
\text { under resource availability, } \\
\text { uncertainty and cycle time }\end{array}$ & {$[158]$} \\
\hline $\mathrm{B} \& \mathrm{~B}$ & $F 3\left|w_{i 1}, w_{i 2}\right| C_{\max }$ & $\begin{array}{l}\text { Randomly generated instances } \\
\text { in a reasonable amount } \\
\text { of the CPU time }\end{array}$ & {$[57]$} \\
\hline $\begin{array}{l}\text { Hybrid Lagrangian metaheuristic } \\
\text { via. volume algorithm }\end{array}$ & $\begin{array}{l}F 2|C D| C_{\max } \text { and } \\
F 2(P)|C D| C_{\max }\end{array}$ & $\begin{array}{l}\text { The cross-docking FSP and a } \\
\text { time-indexed formulation }\end{array}$ & {$[40]$} \\
\hline
\end{tabular}


TABLE 6 . Research on $C_{\max }$ and $\sum C_{j}$ for $F m$ no-wait flow shop scheduling problems.

\begin{tabular}{|c|c|c|c|}
\hline Algorithm & Problem & Findings & Reference \\
\hline $\mathrm{B} \& \mathrm{~B}$ & $F m \mid$ prmu $\mid C_{\max }$ & An arbitrary number of machines & {$[20]$} \\
\hline $\mathrm{B} \& \mathrm{~B}$ & $F m \mid$ prmu $\mid C_{\max }$ & A new lower bound & {$[9]$} \\
\hline Heuristics & $F m \mid$ prmu, nwt $\mid C_{\max }$ & Infinite intermediate storage & [121] \\
\hline The SPT-LPT rules & $F m|n w t| C_{\max }, F$ & Mean flow time criterion & {$[110]$} \\
\hline $\mathrm{B} \& \mathrm{~B}$ & $F m \mid$ prmu $\mid C_{\max }$ & $\begin{array}{l}\text { Computation reduced by over } 50 \% \\
\text { for some more significant problems }\end{array}$ & {$[114]$} \\
\hline $\mathrm{B} \& \mathrm{~B}$ & $F m \mid$ prmu $\mid C_{\max }$ & $\begin{array}{l}\text { Some proposed new lower bounds for } \\
\text { a B\&B method }\end{array}$ & {$[87]$} \\
\hline A TSP and approximate algorithm & $F m \mid S D S T$, block $\mid C_{\max }, T$ & $\begin{array}{l}\text { Approximate solutions to the } \\
\text { infinite storage space cases }\end{array}$ & {$[48]$} \\
\hline Optimality conditions & $F m \mid$ prmu $\mid C_{\max }$ & $\begin{array}{l}\text { Formulated a generalization of the } \\
\text { classical FSP }\end{array}$ & {$[150]$} \\
\hline An additive model & $F m \mid$ prmu, $S D S T \mid C_{\max }$ & $\begin{array}{l}\text { Examined the performance of the } \\
\text { additive approximation }\end{array}$ & {$[151]$} \\
\hline $\begin{array}{l}\text { Specially structured processing } \\
\text { time matrices }\end{array}$ & $F m|n w t| C_{\max }$ & $\begin{array}{l}\text { Specially structured distance } \\
\text { matrices for the TSP }\end{array}$ & {$[159]$} \\
\hline A new B\&B & $F m \mid$ prmu $\mid C_{\max }$ & Schedule for the permutation FSP & [54] \\
\hline A heuristic algorithm & $F m \mid$ prmu $\mid C_{\max }, I_{\text {sum }}$ & $\begin{array}{l}\text { Minimized the number of machine } \\
\text { idle intervals }\end{array}$ & {$[68]$} \\
\hline Simple heuristic algorithm & $F m|N W T| C_{\max }$ & $\begin{array}{l}\text { Heuristic preference relations and job } \\
\text { insertion }\end{array}$ & {$[119]$} \\
\hline Heuristic algorithms & $F m|S D S T| C_{\max }, F$ & Separable and SDST & [50] \\
\hline Heuristics TS and SA & $F m \mid$ prmu $\mid C_{\max }, F$ & $\begin{array}{l}\text { Permutation FSP with batch setup } \\
\text { times }\end{array}$ & {$[147]$} \\
\hline Lagrangian relaxation technique & $F m|p r m u| T_{\max }, F$ & Introducing the virtual sequence & {$[75]$} \\
\hline GA & $F m \mid$ prmu $\mid C_{\max }, F$ & $\begin{array}{l}\text { Processing times dependent on } \\
\text { resources }\end{array}$ & {$[52]$} \\
\hline Enhanced TSP-based heuristic & $F m\left|s_{i j k}, p r m u\right| C_{\max }$ & $\begin{array}{l}\text { Hybrid heuristics for the SDST flow } \\
\text { shop and the TSP }\end{array}$ & {$[85]$} \\
\hline $\mathrm{B} \& \mathrm{~B}$ & $F m\left|s_{i j k}, p r m u\right| C_{\max }$ & $\begin{array}{l}\text { Evaluated a B\&B scheme for the } \\
\text { SDST FSP }\end{array}$ & [84] \\
\hline $\begin{array}{l}\text { B\&B and proposed Allahverdi and } \\
\text { Aldowaisan heuristic (PAAH) }\end{array}$ & $F m|n w t| C_{\max }, C_{w}, F$ & $\begin{array}{l}\text { Bicriteria of minimizing a weighted } \\
\text { sum of makespan and TCT }\end{array}$ & {$[5]$} \\
\hline $\begin{array}{l}\text { Hybrid discrete particle swarm } \\
\text { optimization (HDPSO) algorithm }\end{array}$ & $F m|n w t, p r m u| C_{\max }$ & No-idle permutation FSP criteria & {$[105]$} \\
\hline HDDE & $F m|n w t, p r m u| C_{\max }$ & $\begin{array}{l}\text { Permutation to balance global } \\
\text { exploration and local exploitation }\end{array}$ & {$[28]$} \\
\hline $\begin{array}{l}\text { A constructive heuristic and } \\
\text { Rajendran and Chaudhuri } \\
\text { heuristic, and Bertolissi heuristic }\end{array}$ & $F m\left|n w t, d_{j}\right| F$ & Principle of the initial sequence & {$[130]$} \\
\hline Hybrid genetic algorithms (HGA) & $F m|S D S T, p r m u| C_{\max }$ & SDST condition to hybrid GA & {$[88]$} \\
\hline $\begin{array}{l}\text { Hybrid metaheuristic evolutionary } \\
\text { cluster search (ECS_NSL) }\end{array}$ & $F m \mid S T_{s d}$, no-wait,$r_{j} \mid C_{\max }$ & $\begin{array}{l}\text { SDST to an evolutionary method } \\
\text { (ECS_NSL) }\end{array}$ & {$[96]$} \\
\hline $\mathrm{MBO}$ & $F m \mid$ prum, $S D S T \mid C_{\max }$ & Permutation FSP with SDST & [14] \\
\hline $\begin{array}{l}\text { Multi-objective } \\
\text { NEH-MONEH-MMOIG algorithm }\end{array}$ & $F m \mid$ prmu $\mid C_{\max }, F$ & $\begin{array}{l}\text { Productivity-related criterion and a } \\
\text { sustainability-related criterion }\end{array}$ & {$[31]$} \\
\hline BRILS & $F m \mid$ prmu $\mid C_{\max }, \Psi$ & Non-smooth objective function & [39] \\
\hline VBGA and AIS & $F m \mid$ prmu $\mid C_{\max }$ & $\begin{array}{l}\text { Immune-genetic algorithms to the } \\
\text { permutation FSP }\end{array}$ & {$[15]$} \\
\hline $\begin{array}{l}\text { Integer linear programming } \\
\text { approach }\end{array}$ & $F F m \mid n w t$, block $\mid C_{\max }$ & $\begin{array}{l}\text { Two-stage flexible flow shop with a } \\
\text { shared buffer }\end{array}$ & {$[42]$} \\
\hline MNEH constructive heuristics & $F m|n w t| C_{\max }$ & $\begin{array}{l}\text { A set of } 2000 \text {-jobs and } 20 \text {-machine } \\
\text { problems hard-and-large NWFS } \\
\text { problems }\end{array}$ & {$[72]$} \\
\hline
\end{tabular}


TABLE 6. (Continued.)

\begin{tabular}{|c|c|c|c|}
\hline Algorithm & Problem & Findings & Reference \\
\hline Hybrid metaheuristic (ACO-SA) & $F m|n w t| C_{\max }, F$ & $\begin{array}{l}\text { Ant colony algorithms with the } \\
\text { simulated annealing }\end{array}$ & {$[122]$} \\
\hline An enumeration algorithm & $F m\left|n w t, d_{j}\right| C_{\max }$ & $\begin{array}{l}\text { Release date constraints and } \\
\text { makespan criterion }\end{array}$ & {$[128]$} \\
\hline HDTPL & $F m|n w t| C_{\max }, D$ & Hybrid discrete optimization & {$[134]$} \\
\hline Hybrid PSO algorithm & $F m|n w t, T F T| C_{\max }$ & $\begin{array}{l}\text { Minimizing TFT with relatively low } \\
\text { computational efforts }\end{array}$ & {$[16]$} \\
\hline BS-HH & $F m \mid$ prum $\mid C_{\max }$ & $\begin{array}{l}\text { Distributed assembly permutation } \\
\text { flow-shop scheduling problem } \\
\text { (DAPFSP) }\end{array}$ & [73] \\
\hline CMA & $F m|p r m u| C_{\max }, T_{\max }, F$ & $\begin{array}{l}\text { CMA for solving the } \\
\text { multi-objective distributed } \\
\text { permutation flow shop scheduling } \\
\text { problem (MODPFSP) }\end{array}$ & {$[29]$} \\
\hline $\begin{array}{l}\text { MBGA based on NSGA-II and } \\
\text { NEH }\end{array}$ & $F m \mid$ prmu, block $\mid C_{\max }, F$ & $\begin{array}{l}\text { Total flow time under blocking } \\
\text { constraints }\end{array}$ & {$[102]$} \\
\hline Heuristics, CDR by GP & $F m|S D S T| F_{\text {ave }}, T$ & $\begin{array}{l}\text { Effective CDRs for solving a DFFL } \\
\text { problem }\end{array}$ & {$[56]$} \\
\hline $\begin{array}{l}\text { Two quadratic MIPs, and two } \\
\text { constraint programming }(\mathrm{CP}) \\
\text { models and the exact enumeration } \\
\text { algorithm }\end{array}$ & $F m|n w t, d j| C_{\max }$ & $\begin{array}{l}\text { Release date constraints and } \\
\text { makespan criterion }\end{array}$ & {$[129]$} \\
\hline $\begin{array}{l}\text { Metaheuristic based on } \\
\text { probability teaching-learning } \\
\text { mechanism (mPTLM) }\end{array}$ & $F m|n w t| C_{\max }, F$ & Hybrid mTLBO & {$[136]$} \\
\hline HHS & $F m|n| m|P| C_{\max } \pi_{i}, m_{j}$ & $\begin{array}{l}\text { Efficient job-sequence mapping } \\
\text { scheme }\end{array}$ & {$[176]$} \\
\hline DWWO & Fm $\mid$ no-wait $\mid C_{\max }$ & $\begin{array}{l}\text { WWO algorithm to avoid falling into } \\
\text { the local optima }\end{array}$ & {$[177]$} \\
\hline PAAH & $F m \mid$ no-wait $\mid \varepsilon\left(T T / C_{\max }\right)$ & $\begin{array}{l}\text { Reduces the error of the best } \\
\text { existing algorithms A-FISA, } \\
\text { A-MNEH, A-AIG1, R-ILS, and } \\
\text { R-IGA by } 60 \%\end{array}$ & {$[6]$} \\
\hline TPM & $F_{m}\left|n w t, S T_{s i}\right| C_{\max }$ & Sequence-independent and SDST & {$[171]$} \\
\hline Hybrid ACO & $\begin{array}{l}F_{m}\left|P_{j k}, O_{j i}\right| C_{\max }(\Pi)= \\
M C(\Pi)\end{array}$ & $\begin{array}{l}\text { HACO has found the smaller } \\
\text { average NRPD than ALA and GEN-2 }\end{array}$ & {$[36]$} \\
\hline IG & $F_{m}\left|p^{j, h, r+1}, p_{i, h, r}\right| T F T(\Pi), x$ & $\begin{array}{l}\text { DiyND6 is validated through } \\
\text { comprehensive statistical } \\
\text { experimentations }\end{array}$ & {$[67]$} \\
\hline DWWO & $F m|n o-w a i t| C_{\max }$ & $\begin{array}{l}\text { Integrated the IG algorithm into the } \\
\text { framework of the WWO }\end{array}$ & {$[179]$} \\
\hline IGA & $F m\left|c_{j, k, f}, T_{k, f}\right| C_{\max }$ & $\begin{array}{l}\text { Distributed permutation blocking } \\
\text { flow shop scheduling problem } \\
\text { (DBFSP) allowed the modelling of } \\
\text { the scheduling process }\end{array}$ & {$[124]$} \\
\hline ACSNDP & $\begin{array}{l}\operatorname{HFSP}(m>3) \mid F K \\
\left(P m_{1}, \ldots P m_{k}\right) \mid \text { size }_{i j} \mid C_{\max }\end{array}$ & Exploitation abilities of $\mathrm{ACO} / \mathrm{ACS}$ & {$[61]$} \\
\hline FPAPSO and VNS & $F m|n w t| C_{\max }(\Pi)$ & $\begin{array}{l}\text { Avoiding the particles being trapped } \\
\text { in local optima }\end{array}$ & $\begin{array}{l}{[179,} \\
180]\end{array}$ \\
\hline MINLP and HILS & $\begin{array}{l}H_{i j-k} \mid M \\
1 \mid T C_{\min }, \text { cost }_{\text {setup }}\end{array}$ & $\begin{array}{l}\text { Size dimensionality, computational } \\
\text { time, and solvability }\end{array}$ & {$[184]$} \\
\hline DLR-DNEH & $F m|p r m u| C_{m, j}, C_{\max }$ & $\begin{array}{l}\text { DPFSP with total flowtime } \\
\text { criterion }\end{array}$ & {$[108]$} \\
\hline MILP & $F \mid$ nwait $, s_{i, j, k}, P M(j) \mid C_{\max }$ & $\begin{array}{l}\text { Preventive maintenance }(\mathrm{PM}) \\
\text { operations are integrated with } \\
m \text {-machine NWFSP }\end{array}$ & [90] \\
\hline
\end{tabular}


Zhao et al. [177] recommended the future work as if higher efficient local search tactics can be applied to the two parts. Thus, the performance of the DWWO algorithm will be superior. Engin and Guclu [36] proposed that parallel applications be grouped and cross-combined and that the characteristics of no-wait flow shop scheduling techniques be tuned.

Ying and Lin [171] refer several possible directions for further research first by extending the proposed TPM algorithm to solve $F m\left|n w t, S T_{s i}\right| C_{\max }$ and $F m\left|n w t, S T_{s d}\right| C_{\max }$ problems with other constraints, such as those with considering ready times. The future study may consider setup times or the option of using a standardized or independent flow shop [124]. It is usually the case that firms purchase new lines to boost ability, thus outperforming older lines. Both aspects link the problem closer to most industrial environments. Kurdi [61] suggested that the fundamental concept behind the suggested Non-DaemonActions is a promising study issue. It is worth further investigation of other optimization problems as it yields improved premature convergence, primarily applied to HFSPMT, which is the case of optimization problems too intractable combinatorial.

Zhao et al. [179] directed the need to change the factorial representation to decrease the algorithm's complexity with the option of encoding different evolutionary algorithms. The latter involves a biogeography-based optimization and differential evolution algorithm to address the NWFS issues. Zohali et al. [184] directed future research as outspreading the problem and research outcomes to other economic lot-sizing sequencing problems (ELSPs) on various shop floors. The suggested ELSP-HFS may be expanded to instances where distinct products have distinct cycle times.

\subsection{Research results and recommendations on $\sum C_{j}$ for $F m$}

Xiao et al. [164] defined overlapping operations to the no-wait job shop environment in which distinct products can follow distinct routes. Bai et al. [11] researched the flexible flow shop scheduling problem to decrease total $k$-power completion time $\left(F m|r j| \sum C j k, k \geq 2\right)$. Thus, the B\&B algorithm is provided to optimize the smallscale cases where lower bound and branching rule efficiently saves runtime.

Shahvari and Logendran [132] suggested more parameters of the problem, such as capacities for job processing, different machine eligibilities, changing machine availability times, changing job release times, and the stage skipping possibilities. Pessoa and Andrade [111] recommended a primal-dual gap of up to $8 \%$ for the remainder of the cases as the future direction of work for new research avenues. For instance, the structural characteristics of the issue could be recognized to design better upper limits. The aim is to provide a more precise validation of the quality heuristic approaches.

\subsection{Research results and recommendations on $C_{\max }$ for $F F m$}

Fung et al. [42] pointed to the extended minimal covers, and the integer programming model with valid inequalities are the causes. The investigation of the structure of a typical schedule can be a future direction. Liu et al. [76] recommended the unlimited capacity of the buffers. Since the scheduling issue with the statedependent setup time is a reasonably new study subject, the complexity findings are still open. The IoT-based scheduling practice and methodologies will attract researchers to optimize the energy efficiency target and fuzzy feature of the problem.

Zhonghua et al. [181] implemented variable processing time (FFSP-VPT) to solve a flexible flow shop problem. This paper simulated the selection mode of jobs, detection, processing time, and rework mode. It establishes the FFSP-VPT model and sets up a no-wait two-step encoding mode.

Dios et al. [32] analyzed the empirical hardness, an in-depth study of distinct processing times. Besides, the missing activities can occur at any phase of the shop, and these could be worth studying.

Because of the research gap of this kind of new problem $F F m \mid$ mixed, no-wait, $S T_{S D} \mid C_{\max }$, many extensions such as designing exact methods and metaheuristics are worthy of further research in the future [23]. Zhao et al. [179] suggested the application of HBV to other combinational optimization problems, such as traveling salesman problems, job shop scheduling problems, etc. (Tab. 7). 
TABLE 7. Research summary on $C_{\max }$ for FFm no-wait flow shop scheduling problems.

\begin{tabular}{lll}
\hline \hline Problem & Algorithm & Reference \\
\hline$F F m|S D S T| C w, T w$ & MILP & {$[131]$} \\
$F F m|n w t, b l o c k| C_{\max }$ & ILP & {$[42]$} \\
$F F m|l s m| C_{\max }$ & MILP & {$[62]$} \\
$F F m|S D S T| C, T_{\max }, W w$ & GA & {$[76]$} \\
$F F m(P M) \| r e t r \mid C_{\max }, Z q, D$ & MLPGA & {$[24]$} \\
$F F m(R M) \| T, T_{\max }, C_{\max }$ & NSG & {$[65]$} \\
$F F m|| C_{\max }, F$ & BAT and VPT & {$[181]$} \\
$F F m|s k i p| C_{\max }, W$ & GA $W$ & {$[73]$} \\
$F H m(P M)|s k i p| C_{\max }$ & Dispatching rule & {$[32]$} \\
$F F m \mid S T_{s d}, r j, M j$, skip $\mid \sum w j, T j$ & PSO/LSA & {$[132]$} \\
$F F m \mid$ mixed, no-wait, $S T_{S D} \mid C_{\max }$ & MILP and PIG & {$[23]$} \\
$F F m|n w t, I G| C_{\max }$ & HBV & {$[179]$} \\
$F F m\left|w_{1} C_{\max }+w_{2} f\right| C_{\max } \geq C_{j s}$ & PSO & {$[81]$} \\
\hline
\end{tabular}

\subsection{Research results and recommendations on $C_{\max }$ for $Z_{\text {cost }}$}

Ziaeifar et al. [182] recommended a grouping of the processor project with the hybrid flexible flow shop and can be a future research direction. It is assuming comprehensive consideration and engaging further heuristics or metaheuristics. Babaei et al. [10] proposed the future direction as the other metaheuristics application such as an imperialist competitive algorithm (ICA), particle swarm optimization (PSO), and simulated annealing (SA) to solve MILP model. It is only feasible by considering maintenance operations, infinite workstations and buffers among levels, the stochastic process time, machine breakdown, and invites additional participation.

Sukkerd and Wuttipornpun [149] recommended HGATS algorithm still has some limits. The lot-sizing strategy under concern is only a lot-for-lot. The impact of separate lot-sizing strategies has not been explored, and the overtime is not permitted. All job centers must have the same operational sequence as the permutation schedule. New metaheuristics such as ant colony optimization (ACO), particle swarm optimization (PSO) and simulated annealing (SA) should be examined to find out superior hybrid dynamic algorithms. Multi-criteria optimization and other renowned production shops such as flexible manufacturing shops and job shops and are the main focus here. Thus, more research is required to advance and analyze a novel algorithm to minimize restrictions.

Ramezanian et al. [120] suggested time performance events. It could be regarded as mean tardiness, total completion time, maximum tardiness in place of the cost criteria. It is extending the proposed study to permit other production environments such as job shops and flow shops. Future studies should simplify the asymptotic optimality of the SPTA heuristics to explore the dynamic flow shop learning effect problem. Besides, some metaheuristics such as the local search scheme to DDE algorithm, should be simulated to get a relevant result for medium-scale problems.

Abikarram et al. [1] proposed a mathematical optimization model. It can manage up to 5 machines with 15 jobs per machine and 13 machines with four jobs per machine. It could be feasible to generate results with reasonable solution times without using specially designed metaheuristics. The development of a scalable metaheuristic to solve larger-size problems has been left for future work.

Biele and Monch [17] considered the planning techniques in a rolling horizon setting. The objective is to adjust the effect of many sources of uncertainty. It seems probable to extend the optimization and simulation background proposed by [17]. The simulation model can be used to look more specifically at the improbability of the objective function level. It could be possible by using simulation-based optimization techniques (Tab. 8). 
TABLE 8. Research summary on $C_{\max }$ for $Z_{\text {cost }}$ no-wait flow shop scheduling problems.

\begin{tabular}{lll}
\hline \hline Problem & Algorithm & Reference \\
\hline$H F m(P M) \| C_{\text {max }}, Z_{\text {cost }}$ & GA & {$[182]$} \\
$F m|S D S T| Z_{\text {pih_cost }}, I_{\text {sum }}$ & GA & {$[10]$} \\
$F m \| Z_{\text {cost }}, F$ & HGATS & {$[149]$} \\
$F m|S D S T| Z_{\text {pih_cost }}, C_{\text {max }}$ & Fix-and-relax heuristic (F\&R) & {$[82]$} \\
$F 2 \| C_{\text {max }}, Z_{\text {cost }}$ & MILP and ARIMA & {$[175]$} \\
$F m \| Z_{\text {cost }}, W_{\text {ave }}$ & I-ICA & {$[120]$} \\
$F 2 \| Z_{\text {cost_pih }}, D$ & Two-stage stochastic & {$[66]$} \\
$F m\left|E_{\text {min }}, C T_{i, n, m}\right| Z_{\text {cost }}$ & TLBO and Jaya & {$[89]$} \\
$F m\left|r_{j}, l e\right| f_{k}\left(c_{j}\right)$ & MIP and B\&B & {$[12]$} \\
$F m\left|T W T, c_{j}\right| Z_{\text {cost }}, C_{\max }$ & Random-key GA & {$[17]$} \\
$F m\left|D e * d+\sum w, E\right| Z_{\text {cost }}(\min )$ & Mathematical optimization model & {$[1]$} \\
$F m\left\|Z_{\text {cost }}, F\right\| T E C(\min ) \| C_{\max }$ & AM-VNS & {$[163]$} \\
\hline
\end{tabular}

\section{A quantitative Analysis of the literature}

This review has examined about 300 papers, demonstrating the scheduling group, including hybrid flexible flow shop variants. This investigation surveys thoroughly other appraisals, as $[29,31]$ on multi-objective flow shop constructions and $[8,35]$ on hybrid flow shop problems.

A noteworthy feature of this scheduling group literature is that more than $58 \%$ of the documents have been published after 2010 (Fig. 1). Set over the apparent trend of a growing quantity of publications, while even small matched to those dedicated to other well-developed scheduling concerns, we can reason that FSP with due dates, costing, and lot-sizing are a hopeful field for further developments.

Figure 2 demonstrates the different flow shop problems that have been studied in the literature, showing the number of papers dedicated to each sort of objective utility and performance measure.

The completion-time based is by far the utmost recurrent objective functions: $47 \%$ of the papers' attention on them. A particular event of the completion-time module is makespan, covered by $62 \%$ of the written document. Additional classes of completion-time objectives are broken down into $16 \%$ of the publications. This fact is not shocking, giving the priority of makespan over added objective functions in the literature on scheduling, as directed in $[23,72]$. The remaining $54 \%$ of the literature addresses other cases of objective functions. From them, release/due-date based objective functions represent only the $4 \%$, lot-sizing $5 \%$, and costing $4 \%$ of the publications, advising that these essential objective functions are under-presented, needing more profound attention. This fact has been underlined in particular in $[1,45,66]$.

The circulation of the several optimization techniques employed in the literature is illustrated (Fig. 3). The exact approach mathematical programming and heuristics are mostly used, representing an equal highest share of $13 \%$ of the literature. Another exact approach B\&B is showing $7 \%$ of the literature. Unique examples of metaheuristic, GA, SA, TS, PSO, NSGA II, NEH, MILP, DWWO, VNS/DVNS, ACO, BBO, TLBO, BRILS, and greedy error optimization algorithms are the most commonly used approaches of solution.

The exact approaches appear not to be the most satisfactory for the issue of medium and large size problems. The heuristics and metaheuristic approaches have proved able to bring forward solutions for them of excellent and outstanding caliber. On the other side, the tested metaheuristic methods bring better results than previous ones. [157] put on metaheuristics (A-BBO) to an optimized $m$-machine scheduling problem with merging job sets. These jobs fit two different agents, one of whom was minimized the maximum completion time of jobs, and the other minimized the total tardiness at the same time. Similarly, meta-heuristic suggested a Lagrangian methodology with parallel-docks and time-indexed formulation for cross-dock FSP. 


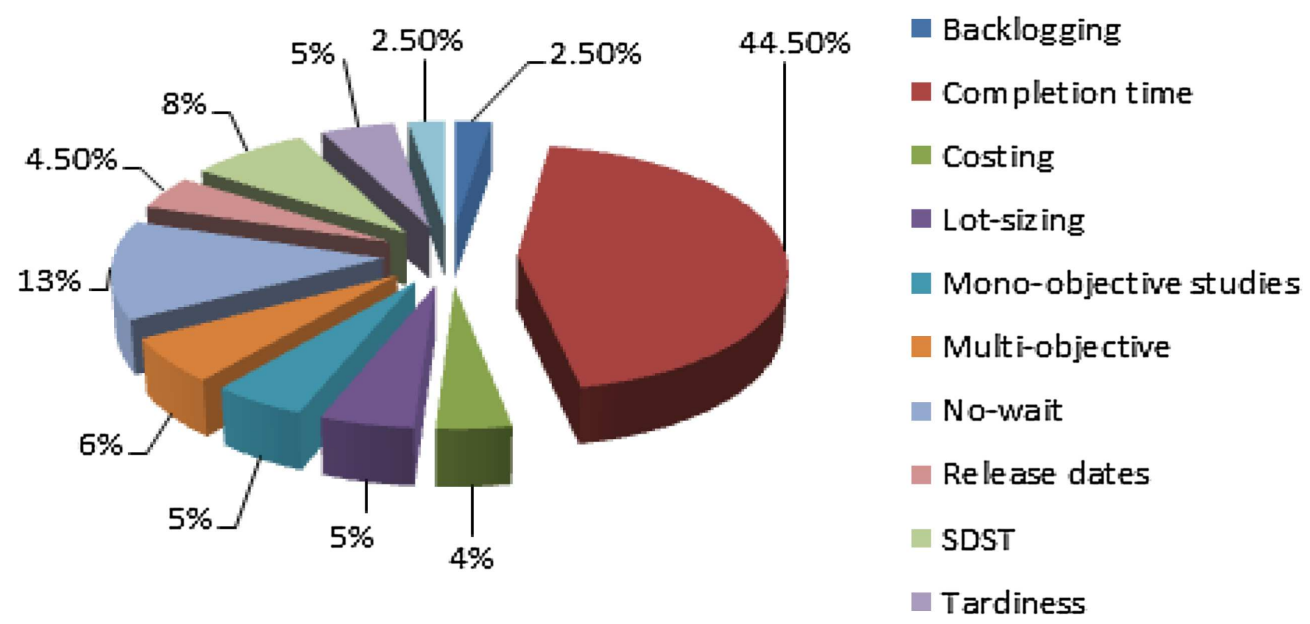

FIGURE 2. Distribution of objective functions considered in the literature.

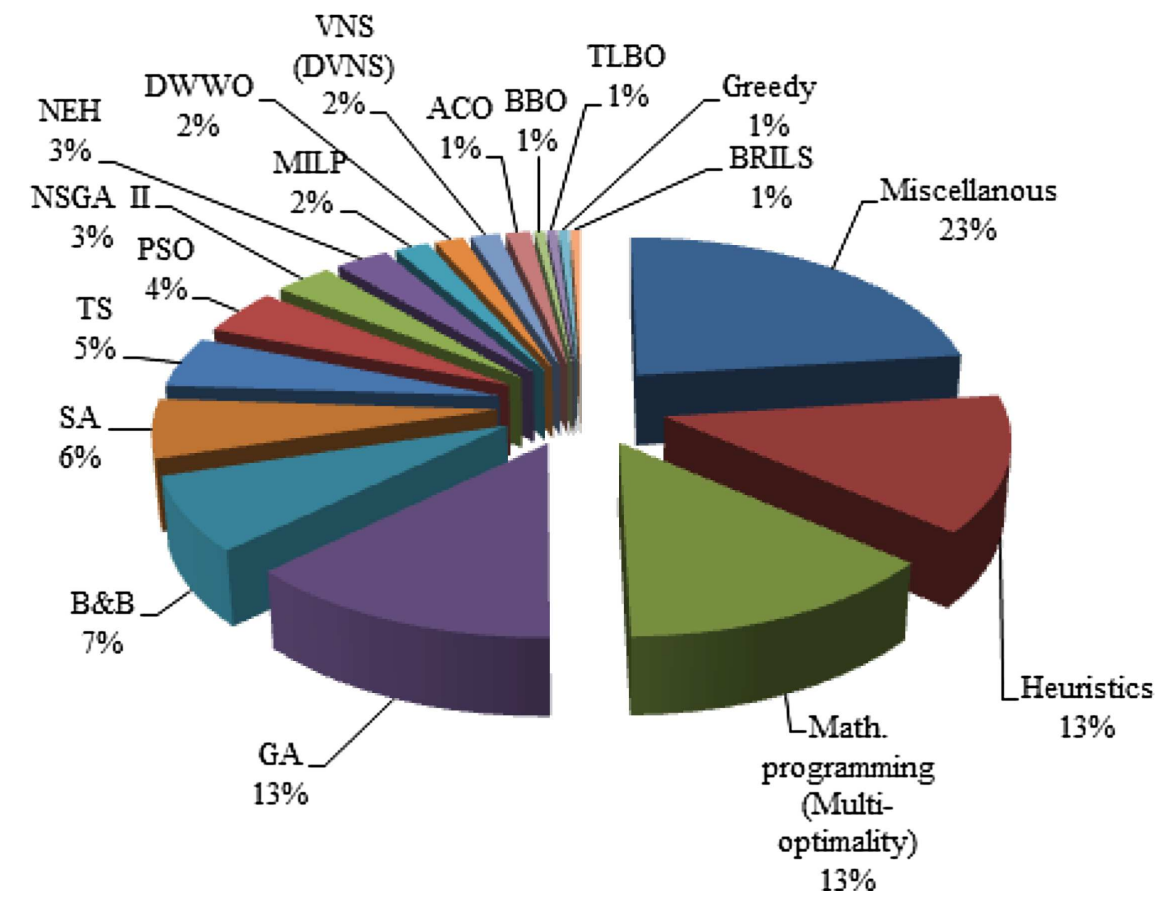

FiguRE 3. Distribution of optimization tools used.

\subsection{Bibliometric analysis}

It is also of concern to present some bibliometric evidence in the literature on FSP. We adopt the style of other analyses, such as $[71,86,131,155]$ who demonstrated that bibliometric statistics could be convenient for the assessment of the study on a new topic. The relevant facts include the list of journals in which papers have been published, the frequency of publication, and its impact. Graham et al. [46] focused his attention on the 
TABLE 9. List of journals depicting two or more articles published on FSP.

\begin{tabular}{|c|c|c|c|}
\hline S. no. & Journal name & $\begin{array}{l}\text { Papers } \\
\text { count }\end{array}$ & Percentage \\
\hline 1 & Computers \& Industrial Engineering & 30 & 10 \\
\hline 2 & The International Journal of Advanced Manufacturing Technology & 29 & 9 \\
\hline 3 & Computers \& Operations Research & 26 & 8 \\
\hline 4 & European Journal of Operational Research & 24 & 8 \\
\hline 5 & Journal of the Operational Research Society & 22 & 7 \\
\hline 6 & Applied Soft Computing & 19 & 6 \\
\hline 7 & Expert Systems with Applications & 17 & 5 \\
\hline 8 & Annals of Operations Research & 12 & 4 \\
\hline 9 & Journal of Cleaner Production & 10 & 3 \\
\hline 10 & IFAC-PapersOnLine & 10 & 3 \\
\hline 11 & International Journal of Production Economics & 10 & 3 \\
\hline 12 & AIIE Transactions & 8 & 3 \\
\hline 13 & Swarm and Evolutionary Computation & 8 & 3 \\
\hline 14 & Journal of Manufacturing Systems & 8 & 3 \\
\hline 15 & Omega & 8 & 3 \\
\hline 16 & Management Science & 7 & 2 \\
\hline 17 & Applied Mathematical Modelling & 7 & 2 \\
\hline 18 & Engineering Applications of Artificial Intelligence & 8 & 3 \\
\hline 19 & Global Journal of Flexible Systems Management & 7 & 2 \\
\hline 20 & Procedia Engineering & 7 & 2 \\
\hline 21 & OR Spectrum & 7 & 2 \\
\hline 22 & International Journal of Industrial Engineering: Theory, Applications and Practice & 4 & 1 \\
\hline 23 & Miscellaneous & 26 & 8 \\
\hline
\end{tabular}

Notes. Percentile calculated over the total of papers reviewed.

latter in the amount of citations reported by Google Scholar when the article was obtained. This fact implies, in our case, June 2019.

The journals mentioned in Table 6 present the review work published in two or more papers. Accordingly, the Computers \& Industrial Engineering Journal and The International Journal of Advanced Manufacturing Technology have remained the outlet for $10 \%$ and $9 \%$ of all the articles respectively in the area. The Computers \& Operations Research Journal and European Journal of Operational Research are closely tracing to each other by a published count of 26 and 24 respectively. As far as conference proceedings are concerned, we consider and have written those indexed in Google Scholar and Scopus.

Journals covering at least one article published on FPS are Annals of Discrete Mathematics, Acta Mathematicae, Applied Mathematics and Com, Archives of Civil and Mechanical Engineering, Chinese Journal of Mechanical Engineering, CIRP Annals-Manufacturing Technology, Information Sciences, Informs Journal of Computing, Journal of Applied Mathematics and Computing, Knowledge-based Systems, Naval Research Logistics, Procedia Manufacturing, and Production Engineering (Tab. 9).

\section{Critical Review}

This article classifies permutation and non-permutation scheduling group problems with the no-wait constraint. The machine and job inputs, manufacturing and assembly lines, setup types, performance measures, dynamic shop environments, and other parameters are the basis. Many possible research venues are proposed. Some articles have individually analyzed the problems. For instance, the problems such as $F 3 \| C_{\max }, F$ were independently addressed by around ten papers, and their results have not been validated. The core permutation 
problem such as $F 2 \| p r m u, r j \mid L_{\max }, F$ and $F 3 \| p r m u \mid C_{\max }, \sum D$ were addressed by 25 papers which are fully validated from the results. On the other side, $F 2 \| n w t \mid C_{\max }, F_{\text {ave }}$ problem which is a core non-permutation no-wait problem, has addressed by about 20 papers. Wang and Liu [160] addressed one problem $F 2(P M)|N W T|$ climax, which is an ideal example of permutation and non-permutation with the no-wait constraint. The beauty of this problem is that it has considered the two-stage no-wait hybrid flow shop problem with a single workstation on the first stage (Tab. 2). The multiple parallel identical workstations on the second stage have to minimize the makespan, considering the NP-hardness of the problem. As the future scope of this problem, researchers can continue perspective to assembly line balancing where the $m$-machine concept is there.

Since the latest problems of the year 2018 and 2019 such as FH3, FHm $\left(\left(R M^{(k)}\right)_{M k=1}\right)\left|M_{j}\right| \sum T_{j}[174]$ becomes a one-of-the most excellent problem as it is referring to a novel programming method for job permutation demonstration. It suggested the dynamic scheduling that utilizes a mechanism to capture the machine to prevent problems with tightness. The job resequencing strategy in workstation buffers is also recommended to moderate the controllability problem. Similarly, problems such as $F 2 \mid C V a R$, no - wait $\mid C_{\max }[158]$ has focused on the residual work content to conditional value-at-risk (CVaR) of the problem. The problem $F 3\left|w_{i 1}, w_{i 2}\right| C_{\max }$ [57] stressed on overlapping waiting time constraints. The dual-problems $F 2|C D| C_{\max }$, and $F 2(P)|C D| C_{\max }$ [40] have focused on Lagrangian metaheuristic approach for the parallel-docks to cross-dock FSP. However, assembly line balancing (ALB) operations and release-date associated performance measures are only addressed in about $12 \%$ of the articles. Therefore, more research on scheduling problems with due/release date and dual ALB performance measures is needed.

The infinite mainstream of research has addressed the job-end time associated performance events, i.e., $C_{\max }$ and $\sum C_{j}$. The $C_{\max }$ performance measure was discussed by more than $55 \%$ of articles, while approximately $20 \%$ of articles discussed the performance measurement of $\sum C_{j}$. Performance measure $\sum C_{j}$ measures the hybrid open shop and job shop and environments. The performance measure $C_{\max }$ explains the flow shop environment. However, Shahvari and Logendran [132] have addressed problem $H F m\left|S T_{s d}, r_{j}, M_{j}, \operatorname{skip}\right| \sum w_{j}, T_{j}$ in which two MILP models were established to find the precise results. It has developed excellent class lower bounds to assess non-exact techniques with due date constraint correspondingly. The critical aspect here is the identification of performance measures. Similarly, job due date performance measure is also addressed in about $10 \%$ of papers. Further, the related performance investigation on scheduling problems with release/due-date interrelated performance procedures is needed.

Regarding the latest research articles, problem $F_{m}\left|n w t, S T_{s i}\right| C_{\max }$ [171] addressed one grouping and crosscombination of two performance measures, SISTs, and SDSTs for the very first time. Another problem $F m\left|c_{j, k, f}, T_{k, f}\right| C_{\max }[124]$ has focused on one research gap which has worked very first time on total tardiness with parallel blocking. It has got attention in the research community. Only $1 \%$ of work has been done on this issue, which is novel with the meager work done on the hybridization of parallel blocking issues.

The permutation and non-permutation scheduling problems of real-life address supplementary than a solocriteria, i.e., multiple-criteria, organize about $18 \%$ of the papers. Most of the current results are for flow shop scheduling environments. Therefore, hybrid open shop or job shop scheduling problems with multi-objective for permutation and non-permutation with the no-wait constraint and its performance measures are venues for new research.

\section{Conclusion AND FUture interventions}

The permutation and non-permutation scheduling with the no-wait constraint have addressed mainly in chemical, manufacturing, plastic, processing, and pharmaceutical industries. It is essential to take the right scheduling decisions to increase productivity and reduce waste. Therefore, scheduling with the no-wait will grow interest in the industries and among researchers.

The work synthesized here has been classified as per the alternatives of the scheduling problem undertaken in them, containing the constraints, objective functions, assumptions, and result approaches functional by the researchers. The completion-time based performance measure is found the most frequent among no-wait flow 
shop problems. The makespan as the objective function is the most intensively studied as more than half of the articles. The other multi-objective criteria and optimization approaches such as due-date and cost analysis, are under-represented in the literature and have covered in less than a quarter of all the publications.

The no-wait constraint under permutation and non-permutation problem is a latest and underdeveloped research theme (matched with conventional production scheduling group), and thus an encouraging subject for advance research directions. This critical review encourages us to recommend some related appraisal issues. (i) The formulation of the bi-criteria problem based on grouping and cross-combination of PFS and NPFS approaches. (ii) The comparative investigation of PFS and NPFS approaches to dynamic and conflicting markets multi-objective problem(s). (iii) The framing of the heuristics matrices for trial and error of machine scheduling about the process index. (iv) The determination of the simulation-optimization approach for batch control and work-in-process. (v) The NPFS with release date and cost-based objective purposes. (vi) The factual case studies are validating the due-date and cost issues. (vii) The execution of novel metaheuristics to report complicated NPFS systems. (viii) The NPFS problems with three or supplementary objectives. (ix) The scheduling uncertainty is an attention-grabbing problem for which rescheduling could aid in advance clarifications.

Acknowledgements. We want to express our sincere gratitude to Editor-in-Chief and the anonymous referees for a comprehensive review of this manuscript and for the remarkable comments, which considerably value-added the quality and appearance of the paper. Also, Thanks to the Mechanical Engineering department, Baba Banda Singh Bahadur Engineering College and I.K. Gujral Punjab Technical University for the technical and administrative support. This research did not have any particular funding from agencies in the public, commercial, or not-for-profit sectors.

\section{REFERENCES}

[1] J.B. Abikarram, K. McConky and R. Proano, Energy cost minimization for unrelated parallel machine scheduling under real time and demand charge pricing. J. Clean. Prod. 208 (2019) 232-242.

[2] F. Ahmadizar and M.H. Farahani, A novel hybrid genetic algorithm for the open shop scheduling problem. Int. J. Adv. Manuf. Technol. 62 (2012) 775-787.

[3] A. Al-Ahmari, A. Ur-Rehman and S. Ali, Decision support system for the selection of advanced manufacturing technologies. J. Eng. Res. 4 (2016) 130-150.

[4] D. Alisantoso, L.P. Khoo and P.Y. Jiang, An immune algorithm approach to the scheduling of a flexible PCB flow shop. Int. J. Adv. Manuf. Technol. 22 (2003) 819-827.

[5] A. Allahverdi and T. Aldowaisan, No-wait flowshops with bicriteria of makespan and total completion time. J. Oper. Res. Soc. 53 (2002) 1004-1015.

[6] A. Allahverdi, H. Aydilek and A. Aydilek, No-wait flowshop scheduling problem with two criteria; total tardiness and makespan. Eur. J. Oper. Res. 269 (2018) 590-601.

[7] A. Allahverdi, H. Aydilek and A. Aydilek, No-wait flowshop scheduling problem with separate setup times to minimize total tardiness subject to makespan. Appl. Math. Comput. 365 (2020) 124688.

[8] H. Allaou and A. Artiba, Integrating simulation and optimization to schedule a hybrid flow shop with maintenance constraints. Comput. Ind. Eng. 47 (2004) 431-450.

[9] S. Ashour, A branch-and-bound algorithm for flow shop scheduling problems. J. AIIE Trans. 2 (1970) $172-176$.

[10] M. Babaei, M. Mohammadi and S.M.T.F. Ghomi, A genetic algorithm for the simultaneous lot sizing and scheduling problem in capacitated flow shop with complex setups and backlogging. Int. J. Adv. Manuf. Technol. 70 (2014) 125-134.

[11] D. Bai, J. Liang, B. Liu, M. Tang and Z.H. Zhang, Permutation flow shop scheduling problem to minimize nonlinear objective function with release dates. Comput. Ind. Eng. 112 (2017) 336-347.

[12] D. Bai, M. Tang, Z.H. Zhang and D.R.S.G. Ernesto, Flow shop learning effect scheduling problem with release dates. Omega 78 (2018) 21-38.

[13] J. Behnamian, Scheduling and worker assignment problems on hybrid flowshop with cost-related objective function. Int. J. Adv. Manuf. Technol. 74 (2014) 267-283.

[14] I. Benkalai, D. Rebaine, C. Gagné and P. Baptiste, The migrating birds optimization metaheuristic for the permutation flow shop with sequence-dependent setup times. IFAC-PapersOnLine 49 (2016) 408-413.

[15] M. Bessedik, F.B.S. Tayeb, H. Cheurfi and A. Blizak, An immunity-based hybrid genetic algorithms for permutation flowshop scheduling problems. Int. J. Adv. Manuf. Technol. 85 (2016) 2459-2469.

[16] L.A. Bewoor, V.C. Prakash and S.U. Sapkal, Production scheduling optimization in foundry using hybrid particle swarm optimization algorithm. Proc. Manuf. 22 (2017) 57-64.

[17] A. Biele and L. Monch, Decomposition methods for cost and tardiness reduction in aircraft manufacturing flow lines. Comput. Oper. Res. 103 (2019) 134-147. 
[18] W. Bozejko, M. Uchronski and M. Wodecki, Parallel metaheuristics for the cyclic flow shop scheduling problem. Comput. Ind. Eng. 95 (2016) 156-163.

[19] W. Bozejko, Z. Hejducki and M. Wodecki, Flowshop scheduling of construction processes with uncertain parameters. Arch. Civil Mech. Eng. 19 (2019) 194-204.

[20] A.P.J. Brown and Z.A. Lomnicki, Some applications of the branch-and-bound algorithm to the machine scheduling problem. Oper. Res. Soc. 17 (1966) 173-186.

[21] M. Bultmann, S. Knust and S. Waldherr, Synchronous flow shop scheduling with pliable jobs. Eur. J. Oper. Res. 270 (2018) 943-956.

[22] H.G. Campbell, R.A. Dudek and M.L. Smith, A heuristic algorithm for the $n$ Job, $m$ machine sequencing problem. Manage. Sci. 16 (1970) 630-637.

[23] C.Y. Cheng, K.C. Ying, S.F. Li and Y.C. Hsieh, Minimizing makespan in mixed no-wait flowshops with sequence-dependent setup times. Comput. Ind. Eng. 130 (2019) 338-347.

[24] H.M. Cho and I.J. Jeong, A two-level method of production planning and scheduling for bi-objective reentrant hybrid flow shop. Comput. Ind. Eng. 106 (2017) 174-181.

[25] R.W. Conway, W.L. Maxwell and L.W. Miller, Theory of Scheduling. Addison-Wesley Publishing, Reading, MA (1967).

[26] F.D. Croce, A. Grosso and F. Salassa, Minimizing total completion time in the two-machine no-idle no-wait flow shop problem. J. Heuristics (2019) 1-15. DOI: 10.1007/s10732-019-09430-z

[27] R.L. Daniels and J.B. Mazzola, A tabu-search heuristic for the flexible-resource flow shop scheduling problem. Ann. Oper. Res. 41 (1993) 207-230.

[28] G. Deng and X. Gu, A hybrid discrete differential evolution algorithm for the no-idle permutation flow shop scheduling problem with makespan criterion. Comput. Oper. Res. 39 (2012) 2152-2160.

[29] J. Deng and L. Wang, A competitive memetic algorithm for multi-objective distributed permutation flow shop scheduling problem. Swarm Evol. Comput. 32 (2017) 121-131.

[30] E. Dhouib, J. Teghem and T. Loukil, Non-permutation flowshop scheduling problem with minimal and maximal time lags: theoretical study and heuristic. Ann. Oper. Res. 267 (2018) 101-134.

[31] J.Y. Ding, S. Song and C. Wu, Carbon-efficient scheduling of flow shops by multi-objective optimization. Eur. J. Oper. Res. 248 (2016) 758-771.

[32] M. Dios, V. Fernandez-Viagas and J.M. Framinan, Efficient heuristics for the hybrid flow shop scheduling problem with missing operations. Comput. Ind. Eng. 115 (2018) 88-99.

[33] R. Dubey and A. Gunasekaran, Strategic Management of Sustainable Manufacturing Operation. IGI Global, Hersheys, PE (2016).

[34] R.G. Dyson, Maximin programming, fuzzy linear programming and multi-criteria decision making. J. Oper. Res. Soc. 31 (1980) 263-267.

[35] M. Ebrahimi, S.M.T.F. Ghomi and B. Karimi, Hybrid flow shop scheduling with sequence-dependent family setup time and uncertain due dates. Appl. Math. Model. 38 (2013) 2490-2504.

[36] O. Engin and A. Guclu, A new hybrid ant colony optimization algorithm for solving the no-wait flow shop scheduling problems. Appl. Soft Comput. 72 (2018) 166-176.

[37] C. Fan, Y. Song and Q. Pei, Project schedule with alternative activities and relationships. J. Eng. Res. 5 (2017) $30-49$.

[38] P. Fattahi, S.M.H. Hosseini and F. Jolai, A mathematical model and extension algorithm for assembly flexible flow shop scheduling problem. Int. J. Adv. Manuf. Technol. 65 (2013) 787-802.

[39] A. Ferrer, D. Guimarans, H. Ramalhinho and A.A. Juan, A BRILS metaheuristic for non-smooth flow-shop problems with failure-risk costs. Expert Syst. App. 44 (2016) 177-186.

[40] G.B. Fonseca, T.H. Nogueira and M.G. Ravetti, A hybrid Lagrangian metaheuristic for the cross-docking flow shop scheduling problem. Eur. J. Oper. Res. 275 (2019) 139-154.

[41] Y. Fu, H. Wang, G. Tian, Z. Li and H. Hu, Two-agent stochastic flow shop deteriorating scheduling via a hybrid multi-objective evolutionary algorithm. J. Intell. Manuf. 30 (2018) 2257-2272.

[42] J. Fung, Y. Zinder and G. Singh, Flexible flow shop with storage: complexity and optimisation methods. IFAC-PapersOnLine 49 (2016) 237-242.

[43] K. Govindan, R. Balasundaram, N. Baskar and P. Asokan, A hybrid approach for minimizing makespan in permutation flowshop scheduling. J. Syst. Sci. Syst. Eng. 26 (2017) 50-76.

[44] J. Grabowski and J. Pempera, New block properties for the permutation flow shop problem with application in tabu search. J. Oper. Res. Soc. 52 (2001) 210-220.

[45] J. Grabowski, E. Skubalska and C. Smutnicki, On flow shop scheduling with release and due dates to minimize maximum lateness. J. Oper. Res. Soc. 34 (1983) 615-620.

[46] R.L. Graham, E.L. Lawler, J.K. Lenstra and A.H.G. Kan, Optimization and approximation in deterministic sequencing and scheduling: a survey. Ann. Disc. Math. 5 (1979) 287-326.

[47] A. Gunasekaran, T. Martikainen and P. Yli-Olli, Flexible manufacturing systems: an investigation for research and applications. Eur. J. Oper. Res. 66 (1993) 1-26.

[48] J.N.D. Gupta, Flowshop schedules with sequence dependent setup times. J. Oper. Res. 29 (1986) $206-219$.

[49] J.N.D. Gupta and A.M.A. Hariri, Two-machine flowshop scheduling to minimize the number of tardy jobs. J. Oper. Res. Soc. 48 (1997) 212-220. 
[50] W. Han and P. Dejax, An efficient heuristic based on machine workload for the flowshop scheduling problem with setup and removal. Ann. Oper. Res. 50 (1994) 263-279.

[51] Y. Han, D. Gong, Y. Jin and Q.K. Pan, Evolutionary multi-objective blocking lot-streaming flow shop scheduling with interval processing time. Appl. Soft Comput. 42 (2016) 229-245.

[52] A. Janiak and M.C. Portmann, Genetic algorithm for the permutation flow-shop scheduling problem with linear models of operations. Ann. Oper. Res. 83 (1998) 95-114.

[53] S.M. Johnson, Optimal two and three stage production schedules with setup times included. Nav. Res. Logist. 1 (1953) 61-68.

[54] S. Karabati, P. Kouvelis and A.S. Kiran, Games, critical paths and assignment problems in permutation flow shops and cyclic scheduling flow line environments. J. Oper. Res. Soc. 43 (1992) 241-258.

[55] D. Khorasanian and G. Moslehi, Two-machine flow shop scheduling problem with blocking, multi-task flexibility of the first machine, and preemption. Comput. Oper. Res. 79 (2017) 94-108.

[56] H. Kia, S.H. Ghodsypour and H. Davoudpour, New scheduling rules for a dynamic flexible flow line problem with sequencedependent setup times. J. Ind. Eng. Int. 13 (2017) 297-306.

[57] H.J. Kim and J.H. Lee, Three-machine flow shop scheduling with overlapping waiting time constraints. Comput. Oper. Res. 101 (2019) 93-102.

[58] J.M. Kim, Y.D. Zhou and D.H. Lee, Priority scheduling to minimize the total tardiness for remanufacturing systems with flow-shop-type reprocessing lines. Int. J. Adv. Manuf. Technol. 91 (2017) 3697-3708.

[59] G.M. Komaki, E. Teymourian, V. Kayvanfar and Z. Booyavi, Improved discrete cuckoo optimization algorithm for the threestage assembly flowshop scheduling problem. Comput. Ind. Eng. 105 (2017) 158-173.

[60] P. Kouvelis, R.L. Daniels and G. Vairaktarakis, Robust scheduling of a two-machine flow shop with uncertain processing times. IIE Trans. 32 (2000) 421-432.

[61] M. Kurdi, Ant colony system with a novel non-daemonactions procedure for multiprocessor task scheduling in multistage hybrid flow shop. Swarm Evol. Comput. 44 (2019) 987-1002.

[62] J.L. Lalitha, N. Mohan and V.M. Pillai, Lot streaming in $[N-1](1)+N(m)$ hybrid flow shop. J. Manuf. Syst. 44 (2017) $12-21$.

[63] J.Y. Lee, Y.D. Kim and T.E. Lee, Minimizing total tardiness on parallel machines subject to flexible maintenance. Int. J. Ind. Eng.: Theory App. Pract. 25 (2018) 472-489.

[64] K. Lee, F. Zheng and M.L. Pinedo, Online scheduling of ordered flow shops. Eur. J. Oper. Res. 272 (2019) 50-60.

[65] D. Lei and Y. Zheng, Hybrid flow shop scheduling with assembly operations and key objectives: a novel neighborhood search. Appl. Soft Comput. 61 (2017) 122-128.

[66] Y. Li and G. Hu, Shop floor lot-sizing and scheduling with a two-stage stochastic programming model considering uncertain demand and workforce efficiency. Comput. Ind. Eng. 111 (2017) 263-271.

[67] X. Li, Z. Yang, R. Ruiz, T. Chen and S. Sui, An iterated greedy heuristic for no-wait flow shops with sequence dependent setup times, learning and forgetting effects. Inf. Sci. 453 (2018) 408-425.

[68] C.J. Liao, Minimizing the number of machine idle intervals with minimum makespan in a flow-shop. J. Oper. Res. Soc. 44 (1993) 817-824.

[69] C.J. Liao, E. Tjandradjaja and T.P. Chung, An approach using particle swarm optimization and bottleneck heuristic to solve hybrid flow shop scheduling problem. Appl. Soft Comput. 12 (2012) 1755-1764.

[70] G.E. Liepins and M.R. Hilliard, Genetic algorithms: foundations and applications. Ann. Oper. Res. 21 (1989) $31-57$.

[71] K.S. Lin, Hybrid algorithm for sequencing with bicriteria. J. Optim. Theory App. 39 (1983) 105-124.

[72] S.W. Lin and K.C. Ying, Optimization of makespan for no-wait flowshop scheduling problems using efficient matheuristics. Omega 64 (2016) 115-125.

[73] J. Lin, Z.J. Wang and X. Li, A Backtracking search hyper-heuristic for the distributed assembly flow-shop scheduling problem. Swarm Evol. Comput. 36 (2017) 124-135.

[74] Y. Liu and Z. Feng, Two-machine no-wait flowshop scheduling with learning effect and convex resource-dependent processing times. Comput. Ind. Eng. 75 (2014) 170-175.

[75] G. Liu, P.B. Luh and R. Resch, Scheduling permutation flow shops using the Lagrangian relaxation technique. Ann. Oper. Res. 70 (1997) 171-189.

[76] G.S. Liu, Y. Zhou and H.D. Yang, Minimizing energy consumption and tardiness penalty for fuzzy flow shop scheduling with state-dependent setup time. J. Clean. Prod. 147 (2017) 470-484.

[77] W. Liu, Y. Jin and M. Price, New meta-heuristic for dynamic scheduling in permutation flowshop with new order arrival. Int. J. Adv. Manuf. Technol. 98 (2018) 1817-1830.

[78] Z.A. Lomnicki, A branch-and-bound algorithm for the exact solution of the three-machine scheduling problem. J. Oper. Res. Soc. 16 (1965) 89-100.

[79] C. Low, J.Y. Yeh and K.I. Huang, A robust simulated annealing heuristic for flow shop scheduling problems. Int. J. Adv. Manuf. Technol. 23 (2004) 762-767.

[80] M.K. Marichelvam, O. Tosun and M. Geetha, Hybrid monkey search algorithm for flow shop scheduling problem under makespan and total flow time. Appl. Soft Comput. 55 (2017) 82-92.

[81] M.K. Marichelvam, M. Geetha and O. Tosun, An improved particle swarm optimization algorithm to solve hybrid flowshop scheduling problems with the effect of human factors - a case study. Comput. Oper. Res. 114 (2020) 104812.

[82] O. Masmoudi, A. Yalaoui, Y. Ouazene and H. Chehade, Multi-item capacitated lot-sizing problem in a flow-shop system with energy consideration. IFAC Papers Proc. 49 (2016) 301-306. 
[83] G.B. McMohan and P.G. Burton, Flow-shop scheduling with the branch-and-bound method. Oper. Res. 15 (1967) $373-589$.

[84] R.G.R. Mercado and J.F. Bard, A branch-and-bound algorithm for permutation flow shops with sequence-dependent setup times. IIE Trans. 31 (1999) 721-731.

[85] R.G.R. Mercado and J.F. Bard, An enhanced TSP-based heuristic for makespan minimization in a flow shop with a setup times. J. Heuristics 5 (1999) 53-70.

[86] G. Minella, R. Ruiz and M. Ciavotta, A review and evaluation of multiobjective algorithms for the flowshop scheduling problem. Informs J. Comput. 20 (2008) 451-471.

[87] Y. Minyi, H. Jiye and C. Yongmao, Elimination conditions and lower bounds for the permutation flow shop scheduling problem. Acta Math. Appl. Sin. 2 (1985) 321-331.

[88] M. Mirabi, A novel hybrid genetic algorithm to solve the sequence-dependent permutation flow-shop scheduling problem. Int. J. Adv. Manuf. Technol. 71 (2014) 429-437.

[89] A. Mishra and D. Shrivastava, A TLBO and a Jaya heuristics for permutation flow shop scheduling to minimize the sum of inventory holding and batch delay costs. Comput. Ind. Eng. 124 (2018) 509-522.

[90] H.H. Miyata, M.S. Nagano and J.N.D. Gupta, Integrating preventive maintenance activities to the no-wait flow shop scheduling problem with dependence-sequence setup times and makespan minimization. Comput. Ind. Eng. 135 (2019) 79-104.

[91] V. Modrak, P. Semanco and P. Knuth, Alternative constructive heuristic algorithm for permutation flow shop scheduling problem with makespan criterion. Int. J. Ind. Eng.: Theory App. Pract. 19 (2012) 289-296.

[92] K. Momaya, Strategic flexibility for competitiveness. Global J. Flexible Syst. Manage. 3 (2002) III.

[93] M.F. Morais, M.G. Filho and T.J.P. Boiko, Hybrid flow shop scheduling problems involving setup considerations: a literature review and analysis. Int. J. Ind. Eng.: Theory App. Pract. 20 (2013) 614-630.

[94] S.M. Mousavi, M. Mousakhani and M. Zandieh, Bi-objective hybrid flow shop scheduling: a new local search. Int. J. Adv. Manuf. Technol. 64 (2013) 933-950.

[95] M.S. Nagano and J.V. Moccellin, A high-quality solution constructive heuristic for flow shop sequencing. J. Oper. Res. Soc. 53 (2002) 1374-1379.

[96] M.S. Nagano, A.A. Silva and L.A.N. Lorena, An evolutionary clustering search for the no-wait flow shop problem with sequence dependent setup times. Expert Syst. App. 41 (2014) 3628-2633.

[97] M.S. Nagano, F.L. Rossi and C.P. Tomazella, A new efficient heuristic method for minimizing the total tardiness in a no-idle permutation flow shop. Prod. Eng. 11 (2017) 523-529.

[98] A. Nagar, S.S. Heragu and J. Haddock, A branch-and-bound approach for a two-machine flowshop scheduling problem. J. Oper. Res. Soc. 46 (1995) 721-734.

[99] A. Nagar, S.S. Heragu and J. Haddock, A combined branch-and-bound and genetic algorithm based approach for a flowshop scheduling problem. Ann. Oper. Res. 63 (1996) 397-414.

[100] J. Navaei, S.M.T.F. Ghomi, F. Jolai and A. Mozdgir, Heuristics for an assembly flow-shop with non-identical assembly machines and sequence dependent setup times to minimize sum of holding and delay costs. Comput. Oper. Res. 44 (2014) $52-65$.

[101] Z.H.A.O. Ning, Y.E. Song, L.I. Kaidian and C.H.E.N. Siyu, Effective iterated greedy algorithm for flow-shop scheduling problems with time lags. Chin. J. Mech. Eng. 30 (2017) 652-662.

[102] N. Nouri and T. Ladhari, Evolutionary multi-objective optimization for the multi-machine flow shop scheduling problem under blocking. Ann. Oper. Res. 267 (2017) 413-430.

[103] C. Ozturk and M.A. Ornek, Optimization and constraint based heuristic methods for advanced planning and scheduling systems. Int. J. Ind. Eng.: Theory App. Pract. 23 (2016) 26-48.

[104] D.S. Palmer, Sequencing jobs through a multi-stage process in the minimum total time - a quick method of obtaining a near optimum. J. Oper. Res. Soc. 16 (1965) 101-107.

[105] Q.K. Pan and L. Wang, No-idle permutation flow shop scheduling based on a hybrid discrete particle swarm optimization algorithm. Int. J. Adv. Manuf. Technol. 39 (2008) 796-807.

[106] Q.K. Pan, P.N. Suganthan, J.J. Liang and M.F. Tasgetiren, A local-best harmony search algorithm with dynamic sub-harmony memories for lot-streaming flow shop scheduling problem. Expert Syst. App. 38 (2011) 3252-3259.

[107] Q.K. Pan, L. Wang and L. Gao, A chaotic harmony search algorithm for the flow shop scheduling problem with limited buffers. Appl. Soft Comput. 11 (2011) 5270-5280.

[108] Q.K. Pan, K. Gao, L. Wang, J. Liang and X.Y. Li, Effective heuristics and meta-heuristics to minimize total flowtime for the distributed permutation flowshop problem. Expert Syst. App. 124 (2019) 309-324.

[109] S.S. Panwalkar, Scheduling of a two-machine flowshop with travel time between machines. J. Oper. Res. Soc. 42 (1991) 609-613.

[110] S.S. Panwalkar and C.R. Woollam, Ordered flow shop problems with no in-process waiting. J. Oper. Res. Soc. 31 (1980) 1039-1043.

[111] L.S. Pessoa and C.E. Andrade, Heuristics for a flowshop scheduling problem with stepwise job objective function. Eur. J. Oper. Res. 266 (2018) 950-962.

[112] M.L. Pinedo, Scheduling: Theory, Algorithms, and Systems, 3rd edition, edited by M.L. Pinedo. Springer, New York, NY (2008).

[113] M.L. Pinedo, Scheduling: Theory, Algorithms, and Systems, 4th edition, edited by M.L. Pinedo. Springer, New York, NY (2012).

[114] C.N. Potts, An adaptive branching rule for the permutation flow-shop problem. Eur. J. Oper. Res. 5 (1980) 19-25. 
[115] R. Pugazhenthi and A. Xavior, A genetic algorithm applied heuristic to minimize the makespan in a flow shop. Proc. Eng. 97 (2014) 1735-1744.

[116] S. Pugazhendhi, S. Thiagarajan, C. Rajendran and N. Anantharaman, Generating non-permutation schedules in flowlinebased manufacturing systems with sequence-dependent setup times of jobs: a heuristic approach. Int. J. Adv. Manuf. Technol. 23 (2004) 64-78.

[117] H. Qin, P. Fan, H. Tang, P. Huang, B. Fang and S. Pan, An effective hybrid discrete grey wolf optimizer for the casting production scheduling problem with multi-objective and multi-constraint. Comput. Ind. Eng. 128 (2019) $458-476$.

[118] G. Rabadi, Heuristics, Metaheuristics and Approximate Methods in Planning and Scheduling, edited by G. Rabadi. In Vol. 236 of International Series in Operation Research and Management Science. Springer, New York, NY (2016) 127-140.

[119] C. Rajendran, A no-wait flow shop scheduling heuristic to minimize makespan. J. Oper. Res. Soc. 45 (1994) $472-478$.

[120] R. Ramezanian, S. Mohammadi and A. Cheraghalikhani, Toward an integrated modeling approach for production and delivery operations in flow shop system: trade-off between direct and routing delivery methods. J. Manuf. Syst. 44 (2017) 79-92.

[121] S.S. Reddi and C.V. Ramamoorthy, On the flow-shop scheduling problem with no-wait in process. J. Oper. Res. Soc. 23 (1972) 323-331.

[122] V. Riahi and M. Kazemi, A new hybrid ant colony algorithm for scheduling of no-wait flowshop. Oper. Res. 18 (2016) 55-74.

[123] I. Ribas, R. Companys and X. Tort-Martorell, Efficient heuristics for the parallel blocking flow shop scheduling problem. Expert Syst. App. $\mathbf{7 4}$ (2017) 41-54.

[124] I. Ribas, R. Companys and X.T. Martorell, An iterated greedy algorithm for solving the total tardiness parallel blocking flow shop scheduling problem. Expert Syst. App. 121 (2019) 347-361.

[125] J. Riezebos, G.J. Gaalman and J.N. Gupta, Flow shop scheduling with multiple operations and time lags. J. Intell. Manuf. 6 (1995) 105-115.

[126] H. Rock, Some new results in flow shop scheduling. Z. Oper. Res. 28 (1984) 1-16.

[127] M.A. Salido, J. Escamilla, A. Giret and F. Barber, A genetic algorithm for energy-efficiency in job-shop scheduling. Int. J. Adv. Manuf. Technol. 85 (2016) 1303-1314.

[128] H. Samarghandi and M. Behroozi, An enumeration algorithm for the no-wait flow shop problem with due date constraints. IFAC-PapersOnLine 49 (2016) 1803-1808.

[129] H. Samarghandi and M. Behroozi, On the exact solution of the no-wait flow shop problem with due date constraints. Comput. Oper. Res. 81 (2017) 41-159.

[130] S.U. Sapkal and D. Laha, A heuristic for no-wait flow shop scheduling. Int. J. Adv. Manuf. Technol. 68 (2013) $1327-1338$.

[131] O. Shahvari and R. Logendran, Hybrid flow shop batching and scheduling with a bi-criteria objective. Int. J. Prod. Econ. 179 (2016) 239-258.

[132] O. Shahvari and R. Logendran, A comparison of two stage-based hybrid algorithms for a batch scheduling problem in hybrid flow shop with learning effect. Int. J. Prod. Econ. 195 (2018) 227-248.

[133] W. Shao and D. Pi, A self-guided differential evolution with neighborhood search for permutation flow shop scheduling. Expert Syst. App. 51 (2016) 161-176.

[134] W. Shao, D. Pi and Z. Shao, A hybrid discrete optimization algorithm based on teaching-probabilistic learning mechanism for no-wait flow shop scheduling. Knowl. Based Syst. 107 (2016) 219-234.

[135] W. Shao, D. Pi and Z. Shao, An extended teaching-learning based optimization algorithm for solving no-wait flow shop scheduling problem. Appl. Soft Comput. 61 (2017) 193-210.

[136] W. Shao, D. Pi and Z. Shao, Memetic algorithm with node and edge histogram for no-idle flow shop scheduling problem to minimize the makespan criterion. Appl. Soft Comput. 54 (2017) 164-182.

[137] Z. Shao, D. Pi and W. Shao, Self-adaptive discrete invasive weed optimization for the blocking flow-shop scheduling problem to minimize total tardiness. Comput. Ind. Eng. 111 (2017) 331-351.

[138] Z. Shao, D. Pi, W. Shao and P. Yuan, An efficient discrete invasive weed optimization for blocking flow-shop scheduling problem. Eng. App. Artif. Intell. 78 (2019) 124-141.

[139] Z. Shao, D. Pi and W. Shao, A novel multi-objective discrete water wave optimization for solving multi-objective blocking flow-shop scheduling problem. Knowl. Based Syst. 165 (2019) 110-131.

[140] O.P. Sharma and P. Sushil, Issues in managing manufacturing flexibility. Global J. Flexible Syst. Manage. 3 (2002) 11-29.

[141] M. Sheikhalishahi, N. Eskandari, A. Mashayekhi and A. Azadeh, Multi-objective open shop scheduling by considering human error and preventive maintenance. Appl. Math. Model. 67 (2019) 573-587.

[142] A. Sioud and C. Gagne, Enhanced migrating birds optimization algorithm for the permutation flow shop problem with sequence dependent setup times. Eur. J. Oper. Res. 264 (2018) 66-73.

[143] H. Singh, J.S. Oberoi and D. Singh, Decision-making approaches and heuristics algorithms for multi-objective flow shop scheduling. Int. J. Res. Eng. App. Manage. 5 (2019) 60-66.

[144] H. Singh, J.S. Oberoi and D. Singh, Optimizing a multi-objective flow shop scheduling problem by meta-heuristic approach. Int. J. Res. Eng. App. Manage. 5 (2019) 20-26.

[145] R.D. Smith and R.A. Dudek, A general algorithm for solution of the $n$-job, $M$-machine sequencing problem of the flow shop. Oper. Res. 15 (1967) 71-82.

[146] C. Smutnicki, A two-machine permutation flow shop scheduling problem with buffers. OR Spectr. 20 (1998) $229-235$.

[147] Y.N. Sotskov, T. Tautenhahn and F. Werner, Heuristics for permutation flow shop scheduling with batch setup times. OR Spectr. 18 (1996) 67-80. 
[148] V.A. Strusevich and C.M. Zwaneveld, On non-permutation solutions to some two machine flow shop scheduling problems. Z. Oper. Res. 39 (1994) 305-319.

[149] W. Sukkerd and T. Wuttipornpun, Hybrid genetic algorithm and tabu search for finite capacity material requirement planning system in flexible flow shop with assembly operations. Comput. Ind. Eng. 97 (2016) 157-169.

[150] W. Szwarc, The clustered flow-shop problem. J. Oper. Res. 32 (1988) 315-322.

[151] W. Szwarc and J.J. Liu, An approximate solution of the flow-shop problem with sequence dependent setup times. J. Oper. Res. 33 (1989) 439-451.

[152] B. Tadayon and N. Salmasi, A two-criteria objective function flexible flow shop scheduling problem with machine eligibility constraint. Int. J. Adv. Manuf. Technol. 64 (2013) 1001-1015.

[153] M. Tandon, P.T. Cummings and M.D. LeVan, Flowshop sequencing with non-permutation schedules. Comput. Chem. Eng. 15 (1991) 601-607.

[154] M.K. Tiwari and N.K. Vidyarthi, Solving machine loading problems in a flexible manufacturing system using a genetic algorithm based heuristic approach. Int. J. Prod. Res. 38 (2000) 3357-3384.

[155] V. T'kindt and J.C. Billaut, Multicriteria Scheduling: Theory, Models and Algorithms, 2nd edition, edited by V. T'kindt and J.C. Billaut. Springer-Verlag, Berlin-Heidelberg (2005).

[156] V. T'kindt, N. Monmarche, F. Tercinet and D. Laugt, An ant colony optimization algorithm to solve a 2-machine bicriteria flowshop scheduling problem. Eur. J. Oper. Res. 142 (2002) 250-257.

[157] M. Torkashvand, B. Naderi and S.A. Hosseini, Modelling and scheduling multi-objective flow shop problems with interfering jobs. Appl. Soft Comput. 54 (2017) 221-228.

[158] M. Urgo, A branch-and-bound approach to schedule a no-wait flow shop to minimize the CVaR of the residual work content. Comput. Ind. Eng. 129 (2019) 67-75.

[159] J.A.A. Veen and R. Dal, Solvable cases of the no-wait flow shop scheduling problem. J. Oper. Res. Soc. 22 (1991) 971-980.

[160] S. Wang and M. Liu, A genetic algorithm for two-stage no-wait hybrid flow shop scheduling problem. Comput. Oper. Res. 40 (2013) 1064-1075.

[161] S.Y. Wang, L. Wang, M. Liu and Y. Xu, An effective estimation of distribution algorithm for solving the distributed permutation flow-shop scheduling problem. Int. J. Prod. Econ. 145 (2013) 387-396.

[162] X.Y. Wang, Z. Zhou, X. Zhang, P. Ji and J.B. Wang, Several flow shop scheduling problems with truncated position-based learning effect. Comput. Oper. Res. 40 (2013) 2906-2929.

[163] X. Wu and A. Che, Energy-efficient no-wait permutation flow shop scheduling by adaptive multi-objective variable neighborhood search. Omega 94 (2019) 102117.

[164] Y. Xiao, Y. Yuan, R.Q. Zhang and A. Konak, Non-permutation flow shop scheduling with order acceptance and weighted tardiness. Appl. Math. Comput. 270 (2015) 312-333.

[165] B. Yagmahan and M.M. Yenisey, A multi-objective ant colony system algorithm for flow shop scheduling problem. Expert Syst. App. 37 (2010) 1361-1368.

[166] J. Yan, L. Li, F. Zhao, F. Zhang and Q. Zhao, A multi-level optimization approach for energy-efficient flexible flowshop scheduling. J. Clean. Prod. 137 (2016) 1543-1552.

[167] S. Yanai and T. Fujie, A three-machine permutation flow-shop problem with minimum makespan on the second machine. $J$. Oper. Res. Soc. 57 (2006) 460-468.

[168] H. Ye, W. Li and A. Abedini, An improved heuristic for no-wait flow shop to minimize makespan. J. Manuf. Syst. 44 (2017) $273-279$

[169] K.C. Ying, Solving non-permutation flowshop scheduling problems by an effective iterated greedy heuristic. Int. J. Adv. Manuf. Technol. 38 (2008) 348-354.

[170] K.C. Ying and S.W. Lin, Multi-heuristic desirability ant colony system heuristic for non-permutation flowshop scheduling problems. Int. J. Adv. Manuf. Technol. 33 (2007) 793-802.

[171] K.C. Ying and S.W. Lin, Minimizing makespan for no-wait flowshop scheduling problems with setup times. Comput. Ind. Eng. 121 (2018) 73-81.

[172] Y. Yip, C.Y. Cheng and C. Low, Sequencing of an $M$ machine flow shop with setup, processing and removal times separated. Int. J. Adv. Manuf. Technol. 30 (2006) 286-296.

[173] A.J. Yu and J. Seif, Minimizing tardiness and maintenance costs in flow shop scheduling by a lower-bound-based GA. Comput. Ind. Eng. 97 (2016) 26-40.

[174] C. Yu, Q. Semeraro and A. Matta, A genetic algorithm for the hybrid flow shop scheduling with unrelated machines and machine eligibility. Comput. Oper. Res. 100 (2018) 211-229.

[175] Y. Zhai, K. Biel, F. Zhao and J.W. Sutherland, Dynamic scheduling of a flow shop with on-site wind generation for energy cost reduction under real-time electricity pricing. CIRP Ann. Manuf. Technol. 66 (2017) 41-44.

[176] F. Zhao, Y. Liu, Y. Zhang, W. Ma and C. Zhang, A hybrid harmony search algorithm with efficient job sequence scheme and variable neighborhood search for the permutation flow shop scheduling problems. Eng. App. Artif. Intell. 65 (2017) $178-199$.

[177] F. Zhao, H. Liu, Y. Zhang, W. Ma and C. Zhang, A discrete water wave optimization algorithm for no-wait flow shop scheduling problems. Expert Syst. App. 91 (2018) 347-363.

[178] F. Zhao, L. Zhang, H. Liu, Y. Zhang, W. Ma, C. Zhang and H. Song, An improved water wave optimization algorithm with the single wave mechanism for the no-wait flow-shop scheduling problem. J. Eng. Optim. 51 (2018) 1727-1742.

[179] F. Zhao, S. Qin, G. Yang, W. Ma, C. Zhang and H. Song, A factorial based particle swarm optimization with a population adaptation mechanism for the no-wait flow shop scheduling problem with the makespan objective. Expert Syst. App. 126 (2019) 41-53. 
[180] F. Zhao, S. Qin, Y. Zhang, W. Ma, C. Zhang and H. Song, A hybrid biogeography-based optimization with variable neighborhood search mechanism for no-wait flow shop scheduling problem. Expert Syst. App. 126 (2019) 321-339.

[181] H. Zhonghua, Z. Boqiu, L. Hao and G. Wei, Bat algorithm for flexible flow shop scheduling with variable processing time. In: Vol. 690 of Part of the Advances in Intelligent Systems and Computing Book Series. In ICMIR' 17: Proceedings of International Conference on Mechatronics and Intelligent Robotics. (AISC) 1 (2017) 164-171. https://link.springer.com/ conference/icmir.

[182] A. Ziaeifar, R. Tavakkoli-Moghaddam and K. Pichka, Solving a new mathematical model for a hybrid flow shop scheduling problem with a processor assignment by a genetic algorithm. Int. J. Adv. Manuf. Technol. 61 (2012) 339-349.

[183] G.I. Zobolas, C.D. Tarantilis and G. Ioannou, Minimizing makespan in permutation flow shop scheduling problems using a hybrid metaheuristic algorithm. Comput. Oper. Res. 36 (2009) 1249-1267.

[184] H. Zohali, B. Naderi, M. Mohammadi and V. Roshanaei, Reformulation, linearization, and a hybrid iterated local search algorithm for economic lot-sizing and sequencing in hybrid flow shop problems. Comput. Oper. Res. 104 (2019) $127-138$. 